\title{
Deciphering Molecular Cascades in a Novel \\ Acclimatization Strategy for Rapid Ascent to High
}

\section{Altitude}

Altitude variation \& rapid acclimation

Subhojit Paul ${ }^{1}$, Anamika Gangwar ${ }^{1}$, Kalpana Bhargava $^{1} \&$ Yasmin Ahmad $^{1} *$

${ }^{1}$ Defence Institute of Physiology \& Allied Sciences, Defence R\&D Organization, Timarpur, New

Delhi-110054

*Corresponding Author:

Dr. Yasmin Ahmad, Scientist 'D', Peptide \& Proteomics Division, DIPAS, DRDO, Timarpur, New Delhi110054. E-mail- yasminchem@gmail.com

Final Character Count (with spaces): 80,341 


\begin{abstract}
The repercussions of hypobaric hypoxia are dependent upon two factors- time and intensity of exposure. The effects of intensity i.e. variation of altitude are yet unknown although it is a significant factor in terms of acclimatization protocols. In this study we present the effects of acute $(24 \mathrm{~h})$ exposure to high $(10,000 \mathrm{ft})$, very high $(15,000 \mathrm{ft})$ and extreme altitude $(25,000$ ft) zones on lung and plasma using semi-quantitative redox specific transcripts and quantitative proteo-bioinformatics workflow in conjunction with redox stress assays. Our findings indicate that very high altitude exposure elicits systemic redox homeostatic processes due to failure of lung redox homeostasis without causing mortality. We also document a rapid acclimatization protocol causing a shift from 0 to $100 \%$ survival at 25,000 $\mathrm{ft}$ in male SD rats upon rapid induction. Finally we posit the various processes involved and the plasma proteins that can be used to ascertain the acclimatization status of an individual.
\end{abstract}

Keywords: Proteomics/Network biology/cytoskeleton/redox homeostasis/rapid acclimatization. 


\section{INTRODUCTION}

Around 466 million humans reside permanently above $3000 \mathrm{msl}$ in Ethiopia (East Africa), Tibet (Asia), Andes (South America) and elsewhere around the globe[1, 2]. This is above and beyond the annual influx of tourists, athletes and adventurers. Hence, acclimatization or the lack of it, even when not considering the related high-altitude maladies, is a significant socioeconomic process in high-altitude areas. Altitude has been categorized arbitrarily into three zones: High altitude (5,000-11,500 ft); Very high altitude $(11,500-18,000 \mathrm{ft})$ and Extreme altitude $(>18,000 \mathrm{ft})[3]$

The majority of altitude sickness cases have been reported at altitudes $>8,000 \mathrm{ft}[4-6]$. The altitudes $\geq 25,000 \mathrm{ft}$ are considered as "Death zone" as no human body can acclimatize at that altitude. It serves as the upper limit of acclimatization to altitude. Although low temperature, low humidity and inhospitable terrain constitute a part of the collective complications at highaltitude, the basic cause attributed to high altitude maladies is hypobaric hypoxia[7-9].

Hypobaric hypoxia exposure is two-pronged- time of exposure (temporal variation, i.e. acute vs chronic) and intensity of exposure (altitude variation, i.e. high vs very high vs extreme). As per our knowledge, this is the first attempt to understand the effects of altitude variation on the rat lung and plasma proteome in conjunction with biochemical redox stress parameters. Most of the previous studies have focused on the temporal effects of a sample set at a particular altitude regarding acclimatization with most authors discouraging a high rate of ascent[10-12]. Some articles have also discussed the ascent of similar climbers in similar mountain ranges but at different ascent rates with suggestions for identification of susceptible and prophylaxis[13-17]. But the process of acclimatization remains untouched in all the articles cited above let alone any suggestions regarding rapid acclimatization. The process of 
acclimatization as followed by most mountaineers consists of slow graded ascent. But even during and after acclimatization, there are cases of AMS, HACE and HAPE reported[18-21]. The diagnosis of these maladies is mostly dependent on qualitative physiological parameters. The Lake Louise Score for AMS, for example, provides a score based on symptoms such as nausea, quality of sleep and headache, which to a certain extent are subjective parameters based on individual assessment[22]. We therefore confront two long-standing issues related to high-altitude acclimatization. The first is of rapid induction to high altitude. The second, consequently, is the ability to decipher the acclimatization status objectively using a panel of plasma proteins. Hence, we ask if the intensity of hypobaric hypoxia, i.e. altitude variation for acute period provides an alternative method for rapidly acclimatizing to a higher altitude. We have checked the effects of acute ( $24 \mathrm{~h}$ ) exposure to simulated altitudes of 10,000 ft (high altitude zone), 15,000 ft (very high altitude zone) and 25,000 ft (extreme altitude zone) on SD rats at the proteome and oxidative stress specific transcripts levels. Our previous work stating the feasibility and statistical robustness of Sult1A1 as a marker for hypobaric hypoxia stress (and HAPE) and $24 \mathrm{~h}$ being the unique time-point showing maximal perturbations within the proteome[23] are also being re-invoked here in the context of altitude variation. Consequently, based on molecular cascades, can there be preventive diagnosis for establishing objectively if an individual is acclimatizing or not based on molecular events much before life-threatening physiological consequences of hypobaric hypoxia occur. It will be a more objective and quantitative method for determining individuals' acclimatization status in association with the already established subjective and qualitative tests (e.g.-Lake Louise Criteria) further augmenting them.

In present study we report that acute exposure to very high altitude $(15,000 \mathrm{ft})$ causes maximal tolerance to hypobaric hypoxia at the proteome and biochemical levels thereby causing a $100 \%$ shift from mortality to survival during further exposure to extreme altitude of 
$25,000 \mathrm{ft}$. We also observe lung redox homeostasis is completely voided at very high altitudes leading to activation of systemic redox homeostasis. But upon revival of lung redox homeostasis in $25 \mathrm{~K}$ (A) group due to the acclimatization strategy we observe subdued systemic redox homeostasis. Herein, we also state plasma proteins that can indicate an organism's redox status at high, very high and extreme altitude thereby objectively assess its state of acclimatization.

\section{RESULTS}

Survivability and Mortality upon induction to extreme altitude (25,000 ft): Pre-exposure to15,000 ft followed by normobaric normoxia exposure .

Five groups of SD rats were exposed to Normobaric normoxia/Baseline (BL: $744 \mathrm{ft}$ ); 10,000 $\mathrm{ft}(10 \mathrm{~K}$, high altitude zone); 15,000 ft (15K, very high altitude zone) and 25,000 ft (25K, extreme altitude zone) as shown in Fig. 1. The ascent rate was kept very rapid $(589 \mathrm{~m} / \mathrm{min})$. Two groups were exposed to $25,000 \mathrm{ft}$ - one group, $25 \mathrm{~K}$ (D) was exposed directly to $25,000 \mathrm{ft}$ without any acclimatization while the other group, $25 \mathrm{~K}$ (A) went through a very short acclimatization (10 h at 15,000 ft followed by $1 \mathrm{~h}$ of normobaric normoxia before ascent to $25,000 \mathrm{ft}$ ). It was observed that till 15,000 ft there was no mortality while all rats given direct exposure to $25,000 \mathrm{ft}$, i.e. $25 \mathrm{~K}$ (D) group perished (Fig.1). But upon pre-exposure to $15,000 \mathrm{ft}$ (simulated) for $10 \mathrm{~h}$ with subsequent exposure to normobaric normoxia for $1 \mathrm{~h}$ prior to exposure of $25,000 \mathrm{ft}$ (simulated), there was a complete reversal of mortality to $100 \%$ survivability, as observed in the $25 \mathrm{~K}$ (A) group. This phenomenon prompted us to delve into the molecular events causing reversal of mortality to survivability.

Rapid induction causes activation of acute phase signaling and impairment of redox stress management in lung tissue while activating the systemic redox homeostatic mechanisms in 15K group: Benefits in 25K (A) group. 
Since the lung tissue is the primary interface between atmosphere and organism, we began our investigation with the lung proteome (iTRAQ labeled; LC-MS/MS). A total of 117 (10K group), 92 (15K group) and 123 (25K (A) group) proteins were identified (Fig.2a). But in $15 \mathrm{~K}$ group there is unanimous down-regulation with the number of proteins identified being reduced noticeably. $25 \mathrm{~K}$ (A) group to the contrary displays the maximum number of upregulated proteins and minimum number of down-regulated ones. Common proteins between all the three groups from lung tissue was just one while 13 proteins were common between $10 \mathrm{~K}$ and $15 \mathrm{~K}$ groups, 8 proteins were common between $10 \mathrm{~K}$ and $25 \mathrm{~K}(\mathrm{~A})$ and 23 proteins were common between $15 \mathrm{~K}$ and $25 \mathrm{~K}$ (A) groups (Fig.2b). Since we found a lot of proteins in the lung proteome to be correlated to oxidative stress, a PCR array analysis of lung tissue for oxidative stress markers (Supplementary dataset S1) was performed. The clustergram of which revealed that $25 \mathrm{~K}$ (A) group was closer in trend to $10 \mathrm{~K}$ and normoxic groups while opposite to $15 \mathrm{~K}$ group (Fig. 2c).

GO analysis of the lung proteome revealed binding and protein binding processes to be common and dominant across all three groups except in case of $25 \mathrm{~K}$ (A) group where molecular functions dominate (Fig.2d). A mix of high-throughput and low-throughput modules was used for the analysis of lung and plasma proteomes, using LC-MS/MS (iTRAQ labeled) (Supplementary dataset S2) and MALDI-TOF/TOF (Supplementary dataset S3), respectively. While LC-MS/MS provided a huge list of proteins with quantification to understand the underlying causal events in lung, the whittling down of this list was achieved in plasma proteome by MALDI-TOF/TOF. Upon pathway analysis (using IPA) of the plasma proteins, we observed Acute phase response signaling (APRS) and LXR/RXR Activation to be the two most significant pathways (Fig.2d). LXR/RXR Activation was up-regulated in $10 \mathrm{~K}$ (z-score $>2)$; down-regulated in $15 \mathrm{~K}(\mathrm{z}$-score $<-2)$ while it showed no perturbations in 
25K (A) group ( $\mathrm{z}$-score=0). Overall, all these findings indicate a strong impetus towards a systemic stress at $15 \mathrm{~K}$ due to redox imbalance and associated processes.

In Table 1, down-regulation (fold change $\leq 0.6$ ) of CRP, APO H, Fibrinogen alpha and gamma chains, VDBP etc in $15 \mathrm{~K}$ group plasma but a significant increase (fold change value $\geq 1.5$ ) of glutathione peroxidase 3 and hemopexin was observed. Serum albumin, a negative acute phase protein, showed decreased levels $(0.63$ fold $)$ in $15 \mathrm{~K}$ group before recovering $(1.12$ fold) in $25 \mathrm{~K}(\mathrm{~A})$ group.

There were common links in terms of pathways (acute phase and LXR/RXR signaling) and directly in terms of molecules (hemopexin, serum albumin, glutathione peroxidase 3) between the lung proteome and plasma proteome across different proteomics platforms suggesting a certain "unity in diversity" for the platforms and protein sets. As oxidative stress is the principal event of hypobaric hypoxia exposure, we analyzed the ROS and MDA levels in both lung and plasma (Fig.3a \& 3b). We observed that although both lung and plasma had the same trend in ROS generation, MDA levels were quite different. MDA levels (indicator of oxidative damage) were highest in $15 \mathrm{~K}$ group lungs ( $\square 5$ fold) while plasma samples had the highest MDA levels in 10K group ( $\square 1.5$ fold). Both lung and plasma had lower MDA levels in $25 \mathrm{~K}$ (A) group. The results suggest that although the ROS generation continued with hypobaric hypoxia exposure, it was neutralized systemically in $15 \mathrm{~K}$ plasma but caused damage resulting in secondary products like MDA in $15 \mathrm{~K}$ lungs. IPA analysis based extrication of APRS revealed that levels of proteins with anti-oxidant roles as well as roles in inflammatory axis were perturbed (Fig.3c). MCP-1(monocyte chemotactic protein-1) is a chemoattractant for causing the extravasation of circulating monocytes and macrophages out of the blood vessels' endothelium. It subsequently causes inflammation at the site of extravasation[24, 25]. Thus we measured MCP-1 in plasma to assess systemic inflammatory stimulus as per altitude variation (Fig.3d). We observed its levels skyrocket in $10 \mathrm{~K}$ (0.6 
$\mathrm{ng} / \mathrm{ml})$ and further in $15 \mathrm{~K}(0.91 \mathrm{ng} / \mathrm{ml})$ group while $25 \mathrm{~K}(\mathrm{~A})$ had negligible levels $(0.18$ $\mathrm{ng} / \mathrm{ml})$. This indicates remarkable reduction of monocyte infiltration, the causal event of inflammation[26, 27]. In line with the quest for putative markers we analyzed Sult1a1 levels also (Fig.3e) as we had observed it had statistically significant discriminatory powers earlier[23]. In the context of altitude variation also, Sult1a1 proved to be a good indicator of acclimatization as indicated by its similar levels in plasma of normoxic controls and $25 \mathrm{~K}$ (A) group ( $\square 1500 \mu \mathrm{mol} / \mathrm{l})$.

Finally, we also examined the levels of upstream APRS molecules (STAT-3) and effectors (calpain-2) in plasma samples (Fig.3f). Immunoblotting revealed STAT-3 levels are highest in $15 \mathrm{~K}$ group plasma $(\square 10,000 \mathrm{AU})$ indicating a perturbed signaling cascade in $15 \mathrm{~K}$ group while $25 \mathrm{~K}$ (A) group ( $\square 5,000 \mathrm{AU})$ showed modest decline as compared to $15 \mathrm{~K}$ group. In calpain-2 the levels are similar in normoxia and 25K (A) group ( $\square 9000$ AU) indicating reduction in protein misfolding (indicator of oxidative stress) in $25 \mathrm{~K}$ (A) group. It has roles in signal transduction, pulmonary vascular remodeling and cytoskeletal remodeling as well[2830].

As shown in Figures $2 \& 3,15 \mathrm{~K}$ group is the group where there is an offsetting of the redox balance in lung tissue and the activation of systemic redox stress management mechanisms to ensure survival of the organism. But unlike $25 \mathrm{~K}$ (D) group, the $15 \mathrm{~K}$ group had no mortality suggesting activation of the systemic mechanisms against redox stress without causing a mortal threat to the organism.

\section{Perturbed antioxidant reserves in $15 \mathrm{~K}$ group were restored in $25 \mathrm{~K}$ (A) group: Rapid} induction is a systemically feasible process.

Since the oxidative stress response occupied centre stage in lung proteome and transcriptome, we investigated Nrf2 levels in lung (Fig.4a). As was expected, Nrf2 (which mediates oxidative stress response and helps the cell survive) declined in $15 \mathrm{~K}$ group ( $\square 11,000 \mathrm{AU}$ ) 
while $25 \mathrm{~K}$ (A) group showed restoration to normoxic levels ( $\square 17,000$ AU). A downstream effector of the Nrf2 mediated response, peroxiredoxin 6 (Prdx6) also showed abysmal decline in $15 \mathrm{~K}$ group ( $\square 1,000 \mathrm{AU}$ ) before recovering in $25 \mathrm{~K}$ (A) group ( $\square 11,000 \mathrm{AU}$ ) (Fig.4a). Furthermore plasma levels of GPx3 and TR2 were also investigated. GPx3 increased ( $\square 27,000 \mathrm{AU})$ when most other antioxidant enzymes were in decline while TR2 exhibited a decline in $15 \mathrm{~K}$ group ( $\square 7,000 \mathrm{AU}$ ) and recovery in $25 \mathrm{~K}$ (A) ( $\square 10,000$ AU) coinciding with normalization of GPx3 levels ( $\square 11,000$ AU) (Fig.4a). The direct hints in the lung and plasma proteomes regarding the related antioxidant reserves of glutathione (GPx3 in MALDI and LC-MS/MS) and thioredoxin (thioredoxin levels in LC-MS/MS) points to the important, almost essential roles these two had to play in maintaining systemic redox homeostasis. This is also evident in the fact that loss-of-function mutations of thioredoxin are lethal to the zygote[31-33]. LC-MS/MS data showed thioredoxin levels decrease in 15K dramatically (0.126 fold) and increase sharply in $25 \mathrm{~K}$ (A) group (3.158 fold) in lung tissue. TR2 is an enzyme that keeps thioredoxin in reduced state[31]. We observed that its levels were mirroring Trx levels systemically.

The PCR array data for lung tissue also reinforces the fact that $15 \mathrm{~K}$ group had the maximum down-regulation of anti-oxidant proteins (Fig.4b) as seen in GPx3, Prdx6 (fold change $\leq 0.3$ ) \& Txnrd2 (TR2) (fold change $\square 5$ ). Here we found that there were opposite trends between Txnrd2 and others. This again points towards activation of systemic redox homeostatic mechanisms upon failure of lung redox homeostasis, possibly via Nrf2. To investigate this aspect, we investigated central antioxidants like Hpx (Fig.4c), TR2 (Fig.4d), SOD (Fig.4e), GSH (Fig.4f) in both lung and plasma. For all, we observed opposing trends in $15 \mathrm{~K}$ and $25 \mathrm{~K}$ (A) group in lung and plasma. In lung, if there were decreases in $15 \mathrm{~K}$ group $(\mathrm{Hpx}=0.25$ fold change, TR2=0.1 units $/ \mathrm{mg}, \mathrm{SOD}=0.2$ units $/ \mathrm{mg}, \mathrm{GSH}=50 \mu \mathrm{M}$ ); $25 \mathrm{~K}$ (A) group definitely shows rebound $(\mathrm{Hpx}=1$ fold change, TR2=3 units/mg, $\mathrm{SOD}=1$ unit $/ \mathrm{mg}, \mathrm{GSH}=65 \mu \mathrm{M})$. The 
same is also true for plasma in case of $15 \mathrm{~K}$ and $25 \mathrm{~K}$ (A) group. To be concise, plasma antioxidants normalize to base-line levels if the lung anti-oxidants recover (GSH, Hpx) but when the lung anti-oxidants can't recover (SOD) systemic levels of that anti-oxidant remain high to supplement its function. Thus, the systemic redox homeostasis remains effective and circumvents mortality.

\section{Cytoskeletal re-arrangements \& Perturbed housekeeping proteins: Massive down-} regulation in $15 \mathrm{~K}$ group but recovery in $25 \mathrm{~K}(\mathrm{~A})$ group.

Nrf2 mediated stress response requires its translocation into nucleus which is dependent on actin[34, 35]. Nrf2 (Fig.4a) as well as vimentin (Vim) fluctuations (Fig.2c) prompted an investigation into actin and other cytoskeletal elements. Upon closer inspection of lung proteome data (Supplementary dataset S2) we observed a striking effect on cytoskeletal elements due to altitude variation (Fig.5a). Across cytoskeletal proteins, we observed that $15 \mathrm{~K}$ group had drastically lower cytoskeletal proteins while $25 \mathrm{~K}$ (A) group showed recovery with protein levels being close to normoxic levels (BL) (Fig.5b). Moreover, the trinity of housekeeping proteins-actin (5,000 AU vs 15,000 AU), tubulin (17,000 AU vs 33,000 AU) (Fig.5b) and GAPDH (4,000 AU vs 7,000 AU) (Fig.6c) were following the same trend. Immunoblotting confirmed the immense cytoskeletal and housekeeping perturbations in $15 \mathrm{~K}$ group which are restored to normal in $25 \mathrm{~K}$ (A) group. Since we had also observed declining serum albumin levels (0.294) (which bind $\mathrm{Ca}^{2+}$ ions) in $15 \mathrm{~K}$ group lung (Supplementary dataset S2), we assayed $\mathrm{Ca}^{2+}$ levels in lung (Fig.5c). As expected, free $\mathrm{Ca}^{2+}$ levels were the highest in $15 \mathrm{~K}$ group $(\square 5 \mathrm{mg} / \mathrm{dL})$ while all other groups showed similar levels $(1.5-2$ $\mathrm{mg} / \mathrm{dL})$. This maybe one event when finely calibrated is causing a shift from $100 \%$ mortality to $100 \%$ survivability as its involved in various facets of cell signaling, intracellular trafficking and bio-energetics. 
In the narrowest sense, calcium signaling effects in lung could be gauged in the plasma proteome by Vitamin D-binding protein's (VDBP) trend and levels at varying altitudes. Recently, the Vitamin-D axis has been highlighted for lung diseases with emphasis on VDBP[36]. VDBP decreases significantly in $15 \mathrm{~K}$ group (0.61) with recovery in $25 \mathrm{~K}(\mathrm{~A})$ group (0.95) (Supplementary dataset S3). VDBP/VDR axis highlights the bio-energetics aspect as VDR interacts with RXR[37].

Glycolysis, TCA cycle and Lipid metabolism are affected in lung tissue: Maximal dysregulation in $15 K$ group and recovery in $25 K(A)$ group.

LXR/RXR pathway (Fig.6a), due to its up- and down- regulation in plasma of $10 \mathrm{~K}$ and $15 \mathrm{~K}$ groups, respectively before normalizing again in $25 \mathrm{~K}$ (A) group (Fig.2d) was investigated in context of bio-energetics. Also, lung proteome data (Supplementary dataset S2) revealed that most of the enzymes with roles in energy metabolism were unanimously down-regulated in $15 \mathrm{~K}$ group while $25 \mathrm{~K}$ (A) group experienced up-regulation (Fig.6b). RXR $\gamma$ levels were analyzed to better understand not only calcium signaling related processes but the entire gamut of processes (Fig.6a) modulated by RXRs including lipid transport and reverse cholesterol transport[37]. We observed maximum RXR levels ( $\square 15,000 \mathrm{AU})$ in $15 \mathrm{~K}$ group plasma (Fig.6c) indicating an increased systemic stimulus for transcriptional activation while $10 \mathrm{~K}$ and $25 \mathrm{~K}(\mathrm{~A})$ had similar levels $(\square 12,000 \mathrm{AU})$. GAPDH, an essential housekeeping protein required for glycolysis, was found to decrease in $15 \mathrm{~K}$ group lungs $(\square 4,000 \mathrm{AU})$ (Fig.6c). Malate dehydrogenase-1 (MDH-1) level which showed decline in 15K group lungs (0.345 fold change) (Supplementary dataset S2) was found to increase in $15 \mathrm{~K}$ plasma ( $\square 8,000 \mathrm{AU}$ ) (Fig.6c). This again lends credence to the hypothesis that systemic processes were activated when lung specific bio-energetic processes were dys-regulated. Finally to have an overview of the direction in which bio-energetics, particularly the pyruvate-lactate step was progressing, we assessed $\mathrm{NAD}^{+} / \mathrm{NADH}$ levels in lung (Fig.6d). It showed immense 
increase in $15 \mathrm{~K}$ group ( $\square 6 \mathrm{AU}$ ) and a similar decline in $25 \mathrm{~K}$ (A) group ( $\square 1 \mathrm{AU}$ ). This indicates a tendency for increased lactate production so as to regenerate $\mathrm{NAD}^{+}$in $15 \mathrm{~K}$ group lungs.

\section{DISCUSSION}

Great efforts have been made to alleviate high-altitude maladies in terms of strategies like climb high and sleep low; supplemental oxygen; gamow bags and the plethora of medicines (nifedipine, sildenafil) specifically to reduce the patho-physiological effects of hypobaric hypoxia[38-43]. But the stunted growth of acclimatization protocols has fallen woefully short in providing a method for rapid induction/acclimatization to altitude. The current acclimatization schedule, stretching over weeks is not just time-intensive but also involves a greater economic cost and willpower to sustain. In this article, a proof of concept is posited that a shorter acclimatization strategy is not only feasible but can provide effective acclimatization against altitudes close to "death zone". Secondly, protein networks and proteins that regulate/modulate the hypoxic response and provide a proteome based assessment of the acclimatization status of an individual are elucidated. This can be, after requisite testing and quality control in humans, the brother-in-arms for Lake Louise criteria.

Rapid induction to $25,000 \mathrm{ft}$ represents a mortal threat to the organism. In our experiments and in real-world scenarios, one sees rat, mountaineers and aviators (pre-pressurized cabin era) struggle to circumvent mortality upon rapid induction[8]. In case of SD rats and mice, one sees a graded ascent to $\geq 25,000 \mathrm{ft}$ (simulated) with multiple pre-exposures to lower altitudes for increased survival with a restricted ascent rate not beyond $200 \mathrm{~m} / \mathrm{min}$ [44-46]. The nil survivability of $25 \mathrm{~K}$ (D) group was worrisome and its circumvention but within minimum possible time form the core of the entire series of experiments. $25 \mathrm{~K}$ (A) group was put through the shortest possible pre-exposure regimen (goal being rapid acclimatization) but 
the result was complete survival. In order to understand this complete reversal of mortality, we delved into lung tissue and plasma. For translational validity, we went for a highly trusted but low sensitivity; low throughput technique like MALDI-TOF[47] for plasma. The aim was to find the maximum number of perturbations in lung (LC-MS/MS) then understand it in terms of pathway analysis. Finally, the common links with plasma proteome signifying the effects of such exposures was to be determined with limited number of proteins. We observed $15 \mathrm{~K}$ group protein levels were very low throughout in lung. In plasma, there was again a contradiction of sorts in $15 \mathrm{~K}$ group and except some proteins (GPx3, STAT-3, RXR $\gamma$ and $\mathrm{MDH}-1$ ), all proteins either decrease or remain at similar levels as $25 \mathrm{~K}$ (A). When we further investigated the various oxidative stress and antioxidant parameters biochemically, we observed that maximum damage is occurring in the lung and maximum systemic activation of redox homeostasis mechanisms is there in plasma. Thus, only upon failure of lung redox homeostasis is there activation of systemic redox homeostasis. Very high altitude zone causes an intense redox homeostasis upheaval. But as observed through pathway analysis, there are not many overall up- or down- regulations in canonical pathways. In the real world also, there is no mortality observed in $15 \mathrm{~K}$ group. Thus, we can safely state that there is a major systemic activation in $25 \mathrm{~K}$ (A) group of systemic redox homeostasis mechanisms. Oxidative stress specific lung transcripts also indicate a heightened oxidative stress response in $15 \mathrm{~K}$ group while $25 \mathrm{~K}$ (A) group responds in a manner strikingly similar to $10 \mathrm{~K}$ and normoxic groups. This is due to pre-exposure at $15,000 \mathrm{ft}$ (very high altitude) for $10 \mathrm{~h}$ followed by normobaric normoxia exposure for $1 \mathrm{~h}$. Central to redox homeostasis modulation are the glutathione and thioredoxin reserves. One observes that respective peroxidases and reductases related to these two also play very important and crucial roles in countering the oxidative stress and maintaining redox homeostasis. An interesting feature is the rise of both GSH and TRX reductase levels in $25 \mathrm{~K}$ (A) group lung tissue suggesting recovery of redox 
balance while in plasma there is a concomitant decrease in levels of both in $25 \mathrm{~K}$ (A) group. This anti-trend between same/related molecules in lung and plasma strongly indicates that hypobaric hypoxia elicits a systemic redox homeostatic response upon the overwhelming of lung redox homeostasis. Such anti-trends bestow us with a calibration with which to diagnose the acclimatization status of an organism by simply analyzing their plasma. This aspect is further elucidated in terms of a network between lung and plasma and will be elaborated in later paragraphs (Fig.7).

We observed acute phase signaling to play a major role in the initial response to hypobaric hypoxia alongwith redox homeostasis. Shared molecules in both these pathways like hemopexin play a major role in subverting any major damage during the exposure. An interesting feature of this entire study is the involvement of calcium signaling that is expressed in plasma as VDBP fluctuations. Such fluctuations as well as lung tissue specific calcium signaling dependent molecules like Annexins coupled with changes in $\mathrm{Ca} 2+$ levels indicate a thorough involvement of calcium signaling in actuation of hypoxia acclimatization. Since the acute phase signaling also consists of molecules involved in inflammatory processes, we measured not just the levels of proteins observed to fluctuate such as C3 (Supplementary) but also of related effectors like MCP-1. The results were clearly indicative that at very high altitudes, we have a severely pro-inflammatory milieu but in $25 \mathrm{~K}$ (A) group in spite of the extreme altitude we see a huge downfall in MCP-1 levels. This is in complete contradiction to previous studies where hypobaric hypoxia exposure triggers inflammation[48-50]. The pre-exposure regimen is the only plausible reason to explain the dramatic decrease in pro-inflammatory signals at a much higher intensity of hypobaric hypoxia. Hence, we can safely commit that the animals are saved from any pathophysiologies as a function of downregulated inflammatory processes. 
Altitude variation also affects essential cytoskeletal elements and housekeeping proteins. Actin, tubulin and GAPDH levels were found to be drastically reduced in $15 \mathrm{~K}$ group lungs. They rebound to close to normoxic levels in $25 \mathrm{~K}$ (A) group but a fluctuation is observed across the four groups. This is an event we suppose could be causing the lung tissue to fail at extreme altitude as cytoskeletal re-arrangements will affect every single aspect of lung cell functions from metabolism to signaling to endocytosis. This particular event has been noted to be prominent in HAPE cases. HAPE patients also suffer from major re-shuffling and disruption of cytoskeletal elements, particularly actin[51] evident via increased lung permeability[52-54]. The restoration of these elements close to normoxic levels in $25 \mathrm{~K}$ (A) group is again an assurance of the robustness of our pre-exposure regime. Hence, the rebound of all cytoskeletal elements observed in $25 \mathrm{~K}$ (A) group at levels similar to normoxic controls indicate a termination of events that may lead to HAPE at least at the cellular level.

HAPE patients whose metabolome was analyzed were found to have dysregulated glycolysis and upregulated protein catabolic processes $[55,56]$. The analysis of lung proteome also revealed extensive perturbations in metabolic pathways and bio-energetics. We observed multiple enzymes of the glycolysis, TCA and lipid metabolic networks to be severely reduced in $15 \mathrm{~K}$ group indicating a dysregulated metabolism. Also, ATP synthase sub-units were found to be severely marred in the same group indicating inefficient bio-energetics. Upon the pre-exposure, the $25 \mathrm{~K}$ (A) group shows recovery on all these counts which are carried over into the plasma proteome in spite of increased intensity of hypobaric hypoxia. The restoration of the bio-energetics process in $25 \mathrm{~K}$ (A) group is another ace indicator of the robustness of this process of rapid induction to altitude. 
In terms of a network, as visualized in the concluding figure (Fig.7), we observe STAT-3, RXR $\gamma$ and Nrf-2 as messengers modulating the response of various downstream proteins involved in the acute phase response, inflammatory signaling, metabolic processes and cytoskeletal stability. STAT-3 levels decline in $25 \mathrm{~K}$ (A) group to allow for recovery of RXR which stabilizes downstream processes leading to energy homeostasis. Declining STAT-3 also helps reduce inflammatory stimuli via IL-6 signaling. Although there was no significant change in $\mathrm{C} 3$ levels across groups we observe MCP-1 (chemoattractant for monocytes) levels to fall back to normoxic levels after dramatic rise in $15 \mathrm{k}$ group. Also, increasing Calpain-2 subunits reduce levels of redox stress induced misfolded peptides and proteins. As a retrospective effect, we also observe declining free $\mathrm{Ca}^{2+}$ levels in lung and restoration of certain essential cytoskeletal elements like actin, tubulin and vimentin. Thus, cytoskeletal stability is restored in $25 \mathrm{~K}$ (A) group. The restoration of energy homeostasis and cytoskeletal stability is testament to the effectiveness of the acclimatization regimen. However, without the restoration of redox homeostasis both these processes are but temporary relief measures against hypoxia. In this regard, we observe Nrf-2 mediated oxidative stress response as well as STAT-3 decline cause a resurgence of anti-oxidant proteins in the lung. The signature of these processes in the lung can be assessed in the plasma via the protein levels of the mentioned proteins (Fig.7) in plasma. The anti-trends revealed earlier in redox homeostasis (biochemical assays, immunoblots) in lungs and plasma must be accounted for while assessing the panel of plasma proteins shown. In order to make sense out of the various proteins in the panel, all of them must be assessed at baseline, very high altitude and extreme altitude zones. This shall provide a comparative analysis of protein trends. Similar trends as described in this article will indicate a positive acclimatization status while a negative acclimatization status will be described as opposing protein trends. Proteins with potential to detect acclimatization status of individuals going through the stated acclimatization strategy 
are glutathione peroxidase 3 (GPX3), superoxide dismutase 1 (SOD), hemopexin (HPX), catalase, malate dehydrogenase 1 (MDH-1), STAT-3, thioredoxin reductase 2 (TR2), retinoid $\mathrm{X}$ receptor (RXR), tubulin, sulfotransferase $1 \mathrm{~A} 1$ (Sult 1A1) and monocyte chemoattractant protein 1 (MCP-1) (Fig.7).

\section{Study Limitations}

Samples from the $25 \mathrm{~K}$ (D) group were unavailable for comparative analysis with other groups due to widespread mortality in this group. The molecular occurrences that signify the progression of patho-physiological processes ultimately leading to death due to hypobaric hypoxia remain occluded. Also, we have not forayed into chronic exposures after this acclimatization regimen. This we feel is a subject for future research and publications. Trials using human subjects for rapid acclimatization will require further scientific diligence. This can also be a fruitful future endeavor. In spite of the authors' best efforts, these limitations do remain.

\section{Conclusion}

To conclude, our data proves that exposure to very high altitude $(15,000 \mathrm{ft}$ for $10 \mathrm{~h})$ followed by a short normobaric normoxia exposure $(1 \mathrm{~h})$ causes a $100 \%$ shift from mortality to survival during further acute exposure $(24 \mathrm{~h})$ to extreme altitude of $25,000 \mathrm{ft}$. This study suggests the possibility of a new route of rapid acclimatization, which was found to bring a high degree of survival at extreme altitude $(25,000 \mathrm{ft})$ by pre-exposure to $15,000 \mathrm{ft}$, which otherwise showed zero survival rate in simulated condition. We had previously investigated and found a high degree of similarity between rat and human regarding pathways and networks responding to hypobaric hypoxia[57]. This study may therefore stand as a proof of concept to translate the objective of rapid acclimatization without compromising the safety and performance of an organism during extreme hypobaric hypoxia exposure. Secondly, this 
study also provides a putative panel of plasma proteins to objectively state whether the organism is acclimatizing rapidly to extreme altitude upon using the stated acclimatization strategy. Rapid acclimatization, as a process, can potentially thwart many hazards and disasters (natural and man-made) in high-altitude regions. When translated, rapid acclimatization will save many medical contingencies.

\section{Materials and Methods}

\section{Experimental Animals \& Experiment Design}

Age matched (10 week old) male Sprague Dawley rats weighing 200-230 g were used for all the experiments. The animals were housed in polypropylene cages with paddy husk as substratum at $25 \pm 5^{\circ} \mathrm{C}$ with humidity at $50 \pm 5 \%$. Night-day cycles of $12 \mathrm{~h}$ each was maintained. Each cage held 3 rats with provisions for food and water. Animal procedures and experimental protocols were approved by Institutional Animal Ethics Committee (Authorization Number: 27/1999/CPCSEA) and we followed the standards set forth in the Guide for the Care and Use of Laboratory Animals (National Academy of Science, Washington, D.C.).

Forty-five rats $(\mathrm{n}=45)$ were randomly and equally divided into five groups, first Baseline controls (animals not receiving simulated hypobaric hypoxia exposure), 10K (animals exposed to simulated hypobaric hypoxia equivalent to $10,000 \mathrm{ft} / 521 \mathrm{mmHg}$ for $24 \mathrm{~h}$ ), $15 \mathrm{~K}$ (animals exposed to simulated hypobaric hypoxia of 15,000 ft; $429 \mathrm{mmHg}$ for $24 \mathrm{~h}$ ), 25K (A) (animals receiving a pre-exposure at $15,000 \mathrm{ft}$ for $10 \mathrm{~h}$ followed by normobaric normoxia exposure of $1 \mathrm{~h}$ prior to exposure of $25,000 \mathrm{ft}$; $282 \mathrm{mmHg}$ for $24 \mathrm{~h}$, A stands for Acclimatized ) and 25K (D) (animals receiving simulated hypobaric hypoxia exposure of 25,000 ft; $282 \mathrm{mmHg}$ for $24 \mathrm{~h}, \mathrm{D}$ stands for direct exposure, without acclimatization). There 
was no pre-acclimatization protocol followed for any groups except in case of $25 \mathrm{~K}$ (A).

Triplicates were run for each of the five groups with three animals in each run per group.

\section{Hypobaric Hypoxia Exposure and sample collection}

Hypobaric Hypoxia exposure simulation was performed in custom designed hypobaric hypoxia simulation chamber (7 star systems, Delhi, India). The chamber had a constant temperature and humidity of $25 \pm 5^{\circ} \mathrm{C}$ and $50 \pm 5 \%$, respectively and an ascent rate of $587 \mathrm{~m} / \mathrm{min}$ was maintained during the exposure. Airflow of $21 / \mathrm{min}$ was also maintained in the chamber. Animals were provided with food and water inside the chamber. Immediately after completion of exposure, all animals were sacrificed using approved procedures. The blood was collected in EDTA containing tubes which were further processed to obtain plasma. Protease inhibitor cocktail (Cat \# P8340, Sigma, USA) was added to prevent protease activity. Lung samples were rinsed in cold PBS and snap frozen in liquid nitrogen. All the samples were stored in $-80^{\circ} \mathrm{C}$ until further use.

\section{Biochemical assessment of oxidative stress and antioxidant levels}

ROS estimation using DCFHDA

A non-fluorescent lipophilic dye, Dichlorofluorescein diacetate (DCFHDA) (Cat \# C400, Life Technologies, USA), was used to measure ROS levels in both lung tissue homogenate and plasma of all four groups. Once internalized into the cells, it is cleaved into 2,7dichlorofluorescein by intracellular esterases and on combining with ROS cleaved DCF produces fluorescence. The fluorescence produced is directly proportional to the ROS levels. We added $10 \mu \mathrm{l}$ of $10 \mu \mathrm{M}$ DCFHDA to $150 \mu \mathrm{l}$ of lung tissue homogenate $(10 \% \mathrm{w} / \mathrm{v}$ in RIPA buffer, Thermo Fisher Scientific, Waltham, USA) and incubated for 40 minutes at $37^{\circ} \mathrm{C}$ in amber tubes (Borosil, USA) in the dark. For estimation of ROS levels in plasma, samples 
were diluted 1:30 in RIPA buffer and then $150 \mu 1$ of this diluted plasma was incubated with $10 \mu \mathrm{l}$ of $10 \mu \mathrm{M}$ DCFDA at $37^{\circ} \mathrm{C}$ for 40 minutes in dark amber tubes. Finally, fluorescence was measured at $488 \mathrm{~nm}$ excitation and $525 \mathrm{~nm}$ emission wavelengths, respectively using flourimeter (LS45 Luminescence Spectrometer, PerkinElmer, USA). The florescence units were normalized to background and data was then presented as AU per $\mu$ l of sample.

\section{Lipid peroxidation status using MDA Assay}

The method suggested by Ohkawa et al was used to measure lipid peroxidation status in both lung tissue homogenate and plasma [58]. Briefly, $750 \mu$ of trichloroacetic acid (TCA; 20\% w/v in distilled water) and $750 \mu \mathrm{l}$ of thiobarbituric acid $(0.67 \% \mathrm{w} / \mathrm{v}$ in $0.05 \mathrm{M} \mathrm{NaOH})$ were added to $250 \mu \mathrm{l}$ of the lung tissue homogenate and plasma each, in series, incubated in a water bath at $95^{\circ} \mathrm{C}$ for 15 minutes then allowed to cool to room temperature. The mixture was then centrifuged ( $400 \mathrm{~g} ; 5$ minutes). $200 \mu \mathrm{l}$ of the supernatant from each group was added in triplicate in a 96-well plate and optical density was measured at $531 \mathrm{~nm}$ using spectrophotometer (VersaMax ELISA Microplate Reader, Molecular Devices, Sunnyvale, CA, USA). The data was normalized with protein content of the samples estimated using standard Bradford's assay and subsequently represented as $\mu \mathrm{mol} \mathrm{MDA} / \mathrm{mg}$ of protein

\section{Estimation of Superoxide Dismutase activity}

Quantification of Superoxide dismutase activity was accomplished using Enzychrome ${ }^{\mathrm{TM}}$ superoxide dismutase assay kit (Cat \# ESOD-100, Bioassay systems, USA) as per the manufacturer's instructions. In concise form, $20 \mu \mathrm{L}$ standard or plasma/lung tissue homogenate samples were added in triplicate to a 96 well plate. Then $160 \mu \mathrm{L}$ working reagent containing assay buffer, xanthine and WST-1 were added to each well in given order. Optical density was measured immediately at $430 \mathrm{~nm}\left(\mathrm{OD}_{0}\right)$ and then plate was incubated at $25^{\circ} \mathrm{C}$ for 60 minutes. Again, optical density was measured at $430 \mathrm{~nm}\left(\mathrm{OD}_{60}\right)$. Finally the 
concentration of SOD was measured using $\Delta \Delta \mathrm{OD}$ vs SOD concentration standard curve. Activity was represented as $\mathrm{U} / \mathrm{ml}$.

\section{Estimation of Reduced Glutathione}

Reduced glutathione was measured using EnzyChrom ${ }^{\mathrm{TM}}$ GSH/GSSG Assay kit (Cat. No. EGTT-100, BioAssay Systems, USA) in both lung and plasma samples. Briefly, $25 \mu 1$ lung homogenates and plasma samples from each group were deproteinated using $65 \mu \mathrm{lof} 5 \% \mathrm{wt}$ meta-phosphoric acid. About $12 \mu \mathrm{l}$ of clear supernatant is taken and mixed with $488 \mu \mathrm{l}$ of $1 \mathrm{X}$ Assay buffer. Then, $200 \mu \mathrm{l}$ of the prepared sample was added to a single well of ELISA 96well plate and $100 \mu \mathrm{l}$ Working Reagent (1X Assay buffer, GR enzyme, NADPH \& DTNB) was subsequently added. Absorbance was taken immediately and after $10 \mathrm{~min}$ at $412 \mathrm{~nm}$.

\section{Thioredoxin reductase assay}

Thioredoxin reductase was measured using TRX Reductase assay kit (Cat. \# CS0170, Sigma Aldrich, USA) as per the manufacturer's instructions. Briefly, $7 \mu$ of either lung tissue homogenate or plasma samples were taken and $7 \mu$ Assay buffer, $180 \mu \mathrm{l}$ wash buffer and $6 \mu \mathrm{l}$ dithio-bis-nitrobenzoic acid (DTNB) were added in sequence. $4 \mu \mathrm{l}$ of dilute inhibitor solution was added to a duplicate set of samples, the rest of the protocol being identical for both sample sets. Absorbance was measured for the two duplicate sets every minute at $412 \mathrm{~nm}$. The rate of change in absorbance per unit time $\left(\Delta \mathrm{A}_{412} / \mathrm{min}\right)$ for the set with inhibitor solution was deducted from the sample set without inhibitor to obtain the final $\Delta \mathrm{A}_{412} / \mathrm{min}$. the change in absorbance was plotted as TRX reductase levels in the sample.

\section{Total calcium estimation}

Calcium concentration was estimated in both lung tissue homogenate and plasma using Quantichrom Calcium assay kit (Cat \# DICA-500, BioAssay Systems, USA), as per the 
manufacturer's instruction. Briefly, $5 \mu$ of either plasma and lung samples or standard was added in duplicates to a 96-well plate. Then, $200 \mu \mathrm{l}$ of working reagent was further added and the well contents were mixed by tapping. The plate was incubated for 3 minutes at room temperature, the absorbance was then immediately recorded at $612 \mathrm{~nm}$.

NAD/NADH assay

$\mathrm{NAD} / \mathrm{NADH}$ ratio was measured in lung tissue using EnzyChrom ${ }^{\mathrm{TM}} \mathrm{NAD} / \mathrm{NADH}$ Assay kit (Cat \# E2ND-100, BioAssay Systems, USA) as per manufacturer's instructions. Briefly, two tissue samples from same animal, weighing 20-25 mg each, were taken and homogenized in $100 \mu \mathrm{l}$ of NAD or NADH extraction buffer, respectively. The extracts were heated for 5 min at $60{ }^{\circ} \mathrm{C}$ and $20 \mu \mathrm{l}$ assay buffer followed by $100 \mu \mathrm{l}$ of the opposite extraction buffer were added in sequence. The samples were vortexed and centrifuged (14000 rpm, 5min) and clear supernatant was used for the assay. Each well had $40 \mu \mathrm{l}$ sample or standard and $80 \mu \mathrm{l}$ Working reagent. Absorbance was measured at zero and 15 min interval at $565 \mathrm{~nm}$ at room temperature. Ratio was calculated using the manufacturers' equation.

\section{High throughput proteomics of lung tissue using LC-MS/MS}

Sample preparation

Equal mass of lung tissues excised from similar regions from the representative animals of each experimental group $(\mathrm{N}, 10 \mathrm{~K}, 15 \mathrm{~K}, 25 \mathrm{~K})$ were homogenized on ice in Radioimmunoprecipitation assay (RIPA) buffer $(5 \mathrm{ml})$. Homogenised tissues were then centrifuges at $15000 \mathrm{~g}$ for $10 \mathrm{~min}$ to separate precipitated debris and supernatant was collected. The pellet was further treated with Protein Isolation buffer (ToPI) and centrifuged. The lysate formed was added to the retained supernatant. Quantity of protein in each sample was estimated using Bradford assay. $100 \mu \mathrm{g}$ of protein from each sample was dispensed and 
processed for MS. Processing involved reduction, alkylation and finally precipitation for removal of interfering substances. Then, trypsin digestion was performed overnight. The digested peptides in digestion buffer were labelled with iTRAQ reagents. Each sample was SCX fractionated and the fractions eluted at $75 \mathrm{mM}, 150 \mathrm{mM}, 450 \mathrm{mM}$ ammonium acetate were collected and analyzed individually by nano-LC-MS/MS. The combined data was used for MudPIT.

Mass spectrometry (LC-MS/MS)

Desalting was done using ZipTip and then the samples were speedvac dried before resuspension in mobile phase for LC-MS/MS. Peptides were eluted from the column using a linear acetonitrile gradient from 5 to $45 \%$ acetonitrile over 180 minutes followed by high and low organic washes for another 20 minutes into an LTQ XL mass spectrometer (Thermo Scientific) via a nanospray source with the spray voltage set to $1.8 \mathrm{kV}$ and the ion transfer capillary set at $180^{\circ} \mathrm{C}$. A data-dependent Top 5 method was used where a full MS scan from m/z 400-1500 was followed by MS/MS scans on the five most abundant ions. iTRAQ Ratio > 1.5 are classified as up-regulated, $<0.67$ are classified as downregulated. Ratios from $1.5-$ 0.67 are considered moderate to no changes.

\section{Plasma proteomics using two dimensional gel electrophoresis (2DGE)}

\section{Protein separation by IEF and SDS-PAGE}

Isoelectric focusing was performed with Immobiline Dry Strip, $\mathrm{pH} 4-7,18 \mathrm{~cm}$ (GE Healthcare, Sweden) on IPGphor IEF System (GE Healthcare, Sweden) at constant voltage. The strip was pre-incubated with $350 \mu 1$ rehydration buffer containing $7 \mathrm{M}$ urea, $2 \mathrm{M}$ thiourea, 1.2\% w/v CHAPS, $0.4 \%$ w/v ABS-14, 20 mM dithiothreitol (DTT), 0.25\% v/v pH 
3-10 ampholytes, $0.005 \% \mathrm{w} / \mathrm{v}$ bromophenol blue (BPB) and $300 \mu \mathrm{g}$ protein at room temperature for $18 \mathrm{~h}$. The IEF consisted $500 \mathrm{~V}$ for $7 \mathrm{~h}$ (slow), $1000 \mathrm{~V}$ for $1 \mathrm{~h}$ (linear), $8000 \mathrm{~V}$ $3 \mathrm{~h}$ (gradient), $8000 \mathrm{~V} 3 \mathrm{~h}$ (linear), $10000 \mathrm{~V} 2 \mathrm{~h}$ (gradient) and $10000 \mathrm{~V}$ 1h (linear). Prior to the second-dimensional gel separation, the IPG strips were equilibrated for $2 \times 15$ min with gentle shaking in $6 \mathrm{ml}$ of SDS equilibration buffer [50 mM Tris- $\mathrm{Cl}$ (pH 8.8), $6 \mathrm{M}$ urea, 30\% v/v glycerol, 2\% SDS]. Freshly prepared DTT (2\%, w/v) was added in the first step and iodoacedamide $(2.5 \%, \mathrm{w} / \mathrm{v})$ in the second equilibration step. The second dimension was carried out using EttanDaltSix Electrophoresis System (GE Healthcare, Sweden). The strips were then loaded onto $12 \%$ SDS-polyacrylamide gel and sealed with $0.5 \%$ agarose (containing BPB). The running buffer contained $25 \mathrm{mM}$ Tris- $\mathrm{HCl}, \mathrm{pH} 8.3,192 \mathrm{mM}$ glycine and $0.1 \% \mathrm{w} / \mathrm{v}$ SDS. Electrophoresis was performed at a constant current of $25 \mathrm{~mA}$ per gel at $25^{\circ} \mathrm{C}$ for $6 \mathrm{~h}$.

Silver staining of $2 D$ gels

After gel electrophoresis, proteins were visualized by modified silver staining procedure compatible with MS. The gels were fixed in $50 \% \mathrm{v} / \mathrm{v}$ methanol, $12 \% \mathrm{v} / \mathrm{v}$ acetic acid and $0.05 \% \mathrm{v} / \mathrm{v}$ formaldehyde for $2 \mathrm{~h}$. The fixed gels were then rinsed with $50 \% \mathrm{v} / \mathrm{v}$ ethanol three times for $20 \mathrm{~min}$ each, then again sensitized with $0.02 \% \mathrm{w} / \mathrm{v}$ sodium thiosulfate followed by three washings with Milli-Q water each for 20 seconds. The gels were immersed in $0.1 \% \mathrm{w} / \mathrm{v}$ silver nitrate and $0.075 \% \mathrm{v} / \mathrm{v}$ formaldehyde for $20 \mathrm{~min}$ and rinsed with Milli-Q water twice for 20 second each followed by developing with $6 \%$ sodium carbonate and $0.05 \% \mathrm{v} / \mathrm{v}$ formaldehyde. Finally, the reaction was terminated by adding $12 \% \mathrm{v} / \mathrm{v}$ acetic acid.

\section{Image acquisition and data analysis}

The stained gel images were captured using an Investigator ${ }^{\mathrm{TM} P r o P i c}$ II (Genomics Solutions, UK) and the digitized gel images analyzed using 2D-Progenesis Samespot Software (Non 
Linear Dynamics, USA). Spot matching between all the gels were viewed using the automatic spot detection and normalization tool and edited where appropriate. The relative intensity of individual spots in 2D-GE gels of different time exposure, treatment and control rats were quantified using a gray-scale and the differences between spot pairs were determined. The median differences of relative spot intensities in matched spots were calculated. Protein alterations confirmed in at least four sample pairs were scored as significant.

In gel tryptic digestion of proteins

In gel tryptic digestion of the proteins was performed using $20 \mathrm{ng} / \mu \mathrm{l}$ sequencing grade trypsin, (Cat no.V5111, Promega, USA) protein digestion, silver stained 2-D gels were extensively washed twice at for 10 min each with MilliQ water and differential spots were manually excised and subjected to in-gel digestion. The gel pieces were de-stained in a freshly prepared 1:1 solution of $30 \mathrm{mM}$ potassium ferricyanide and $100 \mathrm{mM}$ sodium thiosulfate for 1-2 min until the brownish colour disappeared. The gel pieces were then quickly rinsed thrice with MilliQ water to stop the reaction. Next, the gel pieces were further washed with $50 \mathrm{mM}$ ammonium bicarbonate/acetonitrile for $15 \mathrm{~min}$ at room temperature. Enough acetonitrile were added to cover gel pieces for shrinking the gel pieces. The gel pieces were rehydrated with $10 \mathrm{mM}$ ammonium bicarbonate for $5 \mathrm{~min}$, followed by incubation with equal volume of acetonitrile for 10 minutes. The gel pieces were again covered with acetonitrile to induce shrinkage and subjected to vacuum drying. The dried gel pieces were treated with $20 \mu \mathrm{l}$ of sequencing grade trypsin overnight at $37^{\circ} \mathrm{C}$. The tryptic digested peptides were sonicated for $10 \mathrm{~min}$ and dried in MAXI dry plus (Heto Holton, UK).

\section{Matrix preparation}


For identification of proteins, CHCA matrix mixed in 50\% ACN in $0.1 \%$ TFA. After mixing, solution was sonicated for 10 minutes and centrifuged at $10000 \mathrm{rpm}$ for 2 minutes. Clear supernatant was used as saturated matrix for spotting.

\section{Protein Identification by MALDI-TOF/TOF}

For PMF, in-gel tryptic peptides were mixed with CHCA matrix and exposed to laser radiation. The matrix was prepared using $70 \%$ acetonitrile and $0.03 \%$ TFA. $0.5 \mathrm{ml}$ each of peptide extract and matrix were mixed and manually spotted onto 384 well AnchorChip sample target (Bruker Daltonics) and dried at room temperature with surface cover. Peptide mass spectra were recorded using an Ultraflex III Tof/Tof mass spectrometer (Bruker Daltonics) with a 384-sample scout source in reflectron mode. The ion acceleration voltage after pulsed extraction was $27000 \mathrm{~V}$. All data was recorded automatically on the MALDITOF/TOF instrument using the three most abundant peptide signals of the corresponding peptide mass fingerprint (PMF) spectrum. The monoisotopic peak list was generated in Post Processing s/w and True peptide mass list was generated by Bruker Flex Analysis software version 3.0 and Biotools ver 3.1 without using the smoothing function and the signal to noise ratio of 20 was set. The generated peptide mass list was searched with MASCOT (http://www.matrixscience.com) using entire Uniprot/Swiss-Prot protein database to find and match the identified protein. Databases searches were performed by using following search parameters; Rattus norvegicus as taxonomy, carbamidomethyl modification of cysteines and possible oxidation of methionine, one missed cleavage, a mass accuracy of \#100 ppm was requested for PMF and for MS/MS searches. For each identified Protein, at least one Peptide was selected for MS/MS (TOF/TOF) to validate the Protein Identity. Instrument was used in Lift mode (TOF/TOF) to obtain MS/MS spectra. Again the Flex Analysis3.0 and Biotools 3.1 s/w were used to generate the fragments mass list and the sequence Tag of peptide. The mass list was sent to database in same way as was done in case of above PMF approach. The mass 
tolerance error of 0.5 Da to 1.0 Da was used for MS/MS ion search. The MS/MS ion search confirmed the protein identity and provided the amino acid sequence of particular peptide.

\section{Network analysis of Proteomics data}

Data obtained from both high throughput LC-MS/MS and 2DGE-MS was curated manually for artefacts and sorted according to the false discovery rate (less than $1 \%$ ) and p value (less than 5\%). Selected lists of proteins with respective fold change were imported into Network analysis tool Ingenuity Pathway analysis (IPA, Qiagen) with inbuilt statistical analysis package. With the set fold change cutoff of 1.3 various integrated programs such as canonical pathways, network of diseases and functions, proteins networks were used to determine key changes in the cellular events, biochemical processes and molecular cascades. A significant positive and negative z-score was used to predict the directionality of the cellular event. Top canonical pathways and molecular events were selected on the basis of minimum p-value.

\section{ELISA}

ELISA assays were performed for MCP-1 (make, model), regucalcin (make, model) and Sulfotransferase 1A1 (make, model). In case of MCP-1 and Regucalcin, the assays were performed in strict adherence of the manufacturer's protocol for plasma and lung tissue homogenate, respectively while in case of Sulfotransferase 1A1, both plasma and lung samples were assayed separately as per the manufacturer's guidelines.

\section{Immunoblotting}

Immunoblotting of proteins were performed in the lung tissue homogenate samples and plasma samples. Sample containing $25 \mu \mathrm{g}$ of total protein were separated on $10 \%$ SDSPAGE gels and transferred onto nitrocellulose/PVDF membrane. The membrane was blocked in 5\% skim milk in PBS-0.1\% Tween-20 (PBST) overnight at $4{ }^{\circ} \mathrm{C}$. Further, the membrane 
was washed three times with PBST for $10 \mathrm{~min}$ each and incubated with their respective primary and secondary antibodies for $2 \mathrm{~h}$ at room temperature. After washing, the membrane was developed by adding chemiluminiscent peroxidase substrate (Cat \# CPS1300, Sigma, USA). Densitometric analysis of autoradiograms was performed using Image $\mathbf{J}$ software (http://rsbweb.nih.gov/ij/).

\section{PCR Array}

RNA isolation and cDNA synthesis

Transcription of antioxidant specific genes was evaluated with quantitative real-time qRTpolymerase chain reaction (PCR) in four experimental groups- Normoxia, 10k, 15k and 25k. Total RNA was isolated from lung tissue using TriReagent as per manufacturers' protocol. Quantification of RNA was done using Biophotometer plus, Eppendorf and RNase-free water. Reverse transcription was initiated promptly after quantification of RNA using High capacity c-DNA Reverse Transcription kit (cat no.4368814, ABI) as per the manufacturer's instructions. The synthesis program appended a single incubation at $42{ }^{\circ} \mathrm{C}$ for $15 \mathrm{~min}$, followed by incubation at $95{ }^{\circ} \mathrm{C}$ for $5 \mathrm{~min}$. The reaction volume was made up to $100 \mu \mathrm{l}$ with MilliQ water. This cDNA was used for Quantitative RT-PCR.

\section{Real time PCR}

Rat RT2 Profiler TM PCRArray profiling the expression of 84 genes related to oxidative stress, ROS metabolism and related oxygen transporter genes from Qiagen (PARN 065Z, Qiagen, USA) was used for analysis of oxidative stress specific transcripts as per the manufacturer's guidelines. Briefly, $1173 \mu \mathrm{l}$ nuclease-free water (AM9937, Ambion, USA), $1150 \mu \mathrm{l} \mathrm{SYBR}$ green $(\mathrm{ABI})$ and $100 \mu \mathrm{l}$ cDNA were mixed in a solution. $25 \mu \mathrm{l}$ was added to each well of the 96-well array plate from this solution. This plate was briefly spun for 20 sec 
at $1100 \mathrm{rpm}$. RT-PCR protocol was set at $95{ }^{\circ} \mathrm{C}$ for $10 \mathrm{mins}$. Then 40 cycles were performed with $95^{\circ} \mathrm{C}$ for 17 seconds and $60^{\circ} \mathrm{C}$ for $1 \mathrm{~min}$. Applied Biosystems StepOnePlus was used for performing the RT-PCR.

\section{Data Analysis}

Analysis was done based on the $\Delta \Delta \mathrm{C}_{\mathrm{T}}$ values. Fold change values for each gene were tabulated and further analysed using Qiagen's RT-PCR data analysis tool (http://pcrdataanalysis.sabiosciences.com/pcr/arrayanalysis.php). Tool provided a quality check step followed by normalization of data with housekeeping genes and then determination of statistically significant up and down-regulated genes. The data was plotted as dotplot and heatmap of individual comparison, additionally a heatmap with hierarchical clustering was also obtained using the manufacturers' online support tool. Additionally, the data was finally analysed using Ingenuity pathway analysis as stated in the protein analysis.

\section{Statistical analysis}

Data sets were analyzed using Graph pad prism (v 5.0). For statistical significance, 1-way analysis of variance (ANOVA) followed by Bonferroni's Multiple Comparison test was applied. Significance was set at $\mathrm{p}<0.05$. In all cases, three independent experiments were carried out. Results were presented as mean value \pm standard error of mean (SEM).

\section{Acknowledgements}

This study was funded by the Defence R\&D Organization, Ministry of Defence, Govt of India under the project DIP-263. Subhojit Paul is a recipient of Senior Research Fellowship, CSIR. Anamika Gangwar is a recipient of Senior Research Fellowship, DST-INSPIRE. Authors acknowledge Dr. Aditya Arya for his creative inputs in designing the concluding figure. Authors also acknowledge Dr. Shantanu Sengupta and Swati Varshney for access to MALDI-TOF facility. 


\section{Author Contributions}

Experiments were conceived by YA and SP. Experiments were performed by SP and AG. Representative figures were designed by SP and AG. Manuscript was written by YA and SP. KB critically evaluated the manuscript.

\section{Conflict of interest}

Authors declare no conflict of interest.

\section{REFERENCES}

1. Center for International Earth Science Information Network (CIESIN)/Columbia University National Aggregates of Geospatial Data: Population, Landscape and Climate Estimates Version 3 (PLACE III). 2012, Center for International Earth Science Information Network (CIESIN)/Columbia University; NASA Socioeconomic Data and Applications Center: Palisades, New York. p. 16.

2. Eichstaedt, C.A., et al., The Andean adaptive toolkit to counteract high altitude maladaptation: genome-wide and phenotypic analysis of the Collas. PLoS One, 2014. 9(3): p. e93314.

3. Paralikar, S.J. and J.H. Paralikar, High-altitude medicine. Indian J Occup Environ Med, 2010. 14(1): p. 6-12.

4. Montgomery, A.B., J. Mills, and J.M. Luce, Incidence of acute mountain sickness at intermediate altitude. Jama, 1989. 261(5): p. 732-734.

5. Dean, A., R. Yip, and R. Hoffmann, High incidence of mild acute mountain sickness in conference attendees at 10000 foot altitude. Journal of Wilderness Medicine, 1990. 1(2): p. 86-92.

6. Maggiorini, M., et al., Prevalence of acute mountain sickness in the Swiss Alps. Bmj, 1990. 301(6756): p. 853-855.

7. Nyaupane, G., et al., Mountaineering on Mt Everest: evolution, economy, ecology and ethics. Mountaineering tourism. New York, NY: Routledge, 2015: p. 265.

8. Blumen, I.J. and K.J. Rinnert, Altitude physiology and the stresses of flight. Air medical journal, 1995. 14(2): p. 87-100.

9. Netzer, N., et al., Hypoxia-Related Altitude IIInesses. Journal of travel medicine, 2013. 20(4): p. 247-255.

10. Basnyat, B. and D.R. Murdoch, High-altitude illness. The Lancet, 2003. 361(9373): p. 19671974.

11. Bärtsch, P. and E.R. Swenson, Acute high-altitude illnesses. New England Journal of Medicine, 2013. 368(24): p. 2294-2302.

12. Hackett, P.H. and R.C. Roach, High-altitude illness. New England Journal of Medicine, 2001. 345(2): p. 107-114.

13. Cremona, G., et al., Pulmonary extravascular fluid accumulation in recreational climbers: $a$ prospective study. The Lancet. 359(9303): p. 303-309. 
14. Gonggalanzi, et al., Acute mountain sickness among tourists visiting the high-altitude city of Lhasa at 3658 m above sea level: a cross-sectional study. Archives of Public Health, 2016. 74: p. 23.

15. Vardy, J., J. Vardy, and K. Judge, Acute mountain sickness and ascent rates in trekkers above $2500 \mathrm{~m}$ in the Nepali Himalaya. Aviat Space Environ Med, 2006. 77(7): p. 742-4.

16. Sartori, C., et al., High altitude impairs nasal transepithelial sodium transport in HAPE-prone subjects. European Respiratory Journal, 2004. 23(6): p. 916-920.

17. Scherrer, U., et al., New insights in the pathogenesis of high-altitude pulmonary edema. Progress in cardiovascular diseases, 2010. 52(6): p. 485-492.

18. Karinen, H., J. Peltonen, and H. Tikkanen, Prevalence of acute mountain sickness among Finnish trekkers on Mount Kilimanjaro, Tanzania: an observational study. High altitude medicine \& biology, 2008. 9(4): p. 301-306.

19. Jackson, S.J., et al., Incidence and predictors of acute mountain sickness among trekkers on Mount Kilimanjaro. High altitude medicine \& biology, 2010. 11(3): p. 217-222.

20. Ren, Y., et al., Incidence of high altitude illnesses among unacclimatized persons who acutely ascended to Tibet. High altitude medicine \& biology, 2010. 11(1): p. 39-42.

21. Schoene, R.B., Illnesses at high altitude. CHEST Journal, 2008. 134(2): p. 402-416.

22. Roach, R., et al., The Lake Louise acute mountain sickness scoring system. Hypoxia and molecular medicine, 1993. 272: p. 4.

23. Ahmad, Y., et al., The proteome of Hypobaric Induced Hypoxic Lung: Insights from Temporal Proteomic Profiling for Biomarker Discovery. Sci Rep, 2015. 5: p. 10681.

24. Deshmane, S.L., et al., Monocyte chemoattractant protein-1 (MCP-1): an overview. J Interferon Cytokine Res, 2009. 29(6): p. 313-26.

25. Türler, A., et al., MCP-1 causes leukocyte recruitment and subsequently endotoxemic ileus in rat. American Journal of Physiology-Gastrointestinal and Liver Physiology, 2002. 282(1): p. G145-G155.

26. Coussens, L.M. and Z. Werb, Inflammation and cancer. Nature, 2002. 420(6917): p. 860-867.

27. Marra, F., et al., Increased expression of monocyte chemotactic protein-1 during active hepatic fibrogenesis: correlation with monocyte infiltration. The American journal of pathology, 1998. 152(2): p. 423.

28. Carragher, N., et al., Calpain 2 and Src dependence distinguishes mesenchymal and amoeboid modes of tumour cell invasion: a link to integrin function. Oncogene, 2006. 25(42): p. 5726.

29. Meng, X., et al., Characterisation of fibronectin-mediated FAK signalling pathways in lung cancer cell migration and invasion. British journal of cancer, 2009. 101(2): p. 327-334.

30. Ma, W., et al., Calpain mediates pulmonary vascular remodeling in rodent models of pulmonary hypertension, and its inhibition attenuates pathologic features of disease. The Journal of clinical investigation, 2011. 121(11).

31. Arnér, E.S. and A. Holmgren, Physiological functions of thioredoxin and thioredoxin reductase. European Journal of Biochemistry, 2000. 267(20): p. 6102-6109.

32. Bosl, M.R., et al., Early embryonic lethality caused by targeted disruption of the mouse selenocysteine tRNA gene (Trsp). Proc Natl Acad Sci U S A, 1997. 94(11): p. 5531-4.

33. Matsui, M., et al., Early embryonic lethality caused by targeted disruption of the mouse thioredoxin gene. Dev Biol, 1996. 178(1): p. 179-85.

34. Kang, K.W., et al., Phosphatidylinositol 3-kinase regulates nuclear translocation of NF-E2related factor 2 through actin rearrangement in response to oxidative stress. Molecular pharmacology, 2002. 62(5): p. 1001-1010.

35. Kang, M.-I., et al., Scaffolding of Keap1 to the actin cytoskeleton controls the function of Nrf2 as key regulator of cytoprotective phase 2 genes. Proceedings of the National Academy of Sciences, 2004. 101(7): p. 2046-2051. 
36. Chishimba, L., et al., The vitamin $D$ axis in the lung: a key role for vitamin D-binding protein. Thorax, 2010. 65(5): p. 456-462.

37. Lefebvre, P., Y. Benomar, and B. Staels, Retinoid $X$ receptors: common heterodimerization partners with distinct functions. Trends in Endocrinology \& Metabolism, 2010. 21(11): p. 676-683.

38. Paul, S., et al., High altitude pulmonary edema: an update on Omics data and redefining susceptibility. Journal of Proteomics \& Bioinformatics, 2015. 8(6): p. 1.

39. Luks, A.M., Do we have a "best practice" for treating high altitude pulmonary edema? High altitude medicine \& biology, 2008. 9(2): p. 111-114.

40. Luks, A.M., et al., Wilderness Medical Society consensus guidelines for the prevention and treatment of acute altitude illness. Wilderness \& environmental medicine, 2010. 21(2): p. 146-155.

41. Maggiorini, M., Prevention and treatment of high-altitude pulmonary edema. Progress in cardiovascular diseases, 2010. 52(6): p. 500-506.

42. Pennardt, A., High-altitude pulmonary edema: diagnosis, prevention, and treatment. Current sports medicine reports, 2013. 12(2): p. 115-119.

43. Luks, A.M., et al., Wilderness Medical Society practice guidelines for the prevention and treatment of acute altitude illness: 2014 update. Wilderness \& environmental medicine, 2014. 25(4): p. S4-S14.

44. YOSHINO, M., et al., Acclimatization to hypobaric hypoxia reduces anaerobic changes in metabolism in rats at high altitude. Biomedical research, 1989. 10(6): p. 459-462.

45. Magalhães, J., et al., Acute and chronic exposition of mice to severe hypoxia: the role of acclimatization against skeletal muscle oxidative stress. International journal of sports medicine, 2005. 26(02): p. 102-109.

46. Meyrick, B. and L. Reid, Hypoxia and incorporation of 3H-thymidine by cells of the rat pulmonary arteries and alveolar wall. The American Journal of Pathology, 1979. 96(1): p. 5170.

47. Sparbier, K., et al., Immuno-MALDI-TOF MS: New perspectives for clinical applications of mass spectrometry. Proteomics, 2009. 9(6): p. 1442-1450.

48. Møller, P., et al., Acute hypoxia and hypoxic exercise induce DNA strand breaks and oxidative DNA damage in humans. The FASEB Journal, 2001. 15(7): p. 1181-1186.

49. Hartmann, G., et al., High altitude increases circulating interleukin-6, interleukin-1 receptor antagonist and C-reactive protein. Cytokine, 2000. 12(3): p. 246-252.

50. Madjdpour, C., et al., Decreased alveolar oxygen induces lung inflammation. American Journal of Physiology-Lung Cellular and Molecular Physiology, 2003. 284(2): p. L360-L367.

51. Sarkar, S., High-Altitude Medicine: The Path from Genomic Insight to Clinical Applications, in Translational Research in Environmental and Occupational Stress. 2014, Springer. p. 217228.

52. Richalet, J.-P., Pro: Corticosteroids Are Useful in the Management of HAPE. High altitude medicine \& biology, 2015. 16(3): p. 186-189.

53. West, J.B., Invited review: pulmonary capillary stress failure. Journal of Applied Physiology, 2000. 89(6): p. 2483-2489.

54. Zhou, G., L. Dada, and J. Sznajder, Regulation of alveolar epithelial function by hypoxia. European Respiratory Journal, 2008. 31(5): p. 1107-1113.

55. Luo, Y., J. Zhu, and Y. Gao, Metabolomic analysis of the plasma of patients with high-altitude pulmonary edema (HAPE) using 1H NMR. Molecular BioSystems, 2012. 8(6): p. 1783-1788.

56. Guo, L., et al., Three plasma metabolite signatures for diagnosing high altitude pulmonary edema. Scientific reports, 2015. 5: p. 15126.

57. Paul, S., K. Bhargava, and Y. Ahmad, The meta-analytical paradigm in an in silico hybrid: Pathways and networks perturbed during exposure to varying degrees of hypobaric hypoxia. Proteomics Clin Appl, 2017. 
58. Ohkawa, H., N. Ohishi, and K. Yagi, Assay for lipid peroxides in animal tissues by thiobarbituric acid reaction. Analytical biochemistry, 1979. 95(2): p. 351-358.

\section{FIGURE LEGENDS}

Figure 1: Study Design. Male SD rats (10 week old; 200-230 g) were exposed to Normobaric normoxia (BL; mmHg; n=9), 10,000 ft (10K; mmHg; $n=9), 15,000 \mathrm{ft}(15 \mathrm{~K} ; \mathrm{mmHg} ; \mathrm{n}=9), 25,000 \mathrm{ft}$ $(25 \mathrm{~K} ; \mathrm{mmHg} ; \mathrm{n}=18)$. Exposure to $25,000 \mathrm{ft}$ was provided to two separate groups. One group (25K (D); $n=9$ ) was exposed directly to $25,000 \mathrm{ft}$ altitude while the other group (25K (A); $=9$ ) was given an acclimatization for $10 \mathrm{~h}$ at $15,000 \mathrm{ft}$ and $1 \mathrm{~h}$ at normobaric normoxia. All altitude exposures were simulated in hypobaric hypoxia chamber with the rate of ascent being $589 \mathrm{~m} / \mathrm{min}$ and temperature $\left(25^{\circ} \mathrm{C}\right)$ and humidity (50\%). Zero animals survived in $25 \mathrm{~K}$ (D) group while all animals (9) survived in $25 \mathrm{~K}$ (A) group. Upon biochemical and omics-based investigation on lung tissue and plasma, we observed $15 \mathrm{~K}$ group (yellow) had maximum perturbations in redox and energy homeostasis with failing housekeeping functions in lung tissue while all other groups (black) had minimal/reduced molecular perturbations. 25K (D) group (red) could not be probed as all animals in this group died on exposure. The experiment was repeated thrice for statistical significance with each group having three rats per experimental replicate.

\section{Figure 2: Overview of Proteome and redox-specific transcripts alongwith affected pathways.}

a) The total number of proteins (blue) identified in $10 \mathrm{~K}, 15 \mathrm{~K}$ and $25 \mathrm{~K}$ (A) groups alongwith number of up-regulated (maroon) and down-regulated (green) proteins during LC-MS/MS (iTRAQ labeled) analysis of lung tissue. $15 \mathrm{~K}$ group has the least number of proteins identified (92) with the maximum number of down-regulated proteins (80). 25K (A) group had the highest number of proteins identified (123) among which 32 were up-regulated and 10 down-regulated. $10 \mathrm{~K}$ had 117 proteins identified with 15 up-regulated and 16 downregulated proteins. Fold change value greater than 1.5 fold was considered up-regulation while fold change value lesser than 0.67 was considered as down-regulation.

b) Venn diagram showing overlapping up- and down- regulated proteins among the proteins in $10 \mathrm{~K}$ (blue), 15K (yellow) and 25K (A) (pink) groups. Fold change values of 1.5 or more and 0.66 or less were the criteria for choosing up-regulated and down-regulated proteins respectively. Venn diagram was created using Venny 2.1 (Oliveros, J.C. (2007-2015) Venny. An interactive tool for comparing lists with Venn's diagrams. http://bioinfogp.cnb.csic.es/tools/venny/index.html). Only a single protein was common between $10 \mathrm{~K}, 15 \mathrm{~K}$ and $25 \mathrm{~K}$ (A) groups. The maximum number of overlapping proteins was between $15 \mathrm{~K}$ and $25 \mathrm{~K}$ (A) groups (22). The minimum number of overlapping proteins was between $10 \mathrm{~K}$ and $25 \mathrm{~K}$ (A) (08).

c) Clustergram with maximum join type hierarchical clustering comparing the redox-stress specific transcripts' up-regulation (red) and down-regulation (green) among BL (baselinenormoxic control), $10 \mathrm{~K}, 15 \mathrm{~K}$ and $25 \mathrm{~K}$ (A) groups. PCR-Array specific to redox-stress specific transcripts was used to generate $\Delta \Delta \mathrm{C}_{\mathrm{T}}$ values (RT-PCR) for all four groups (BL, $10 \mathrm{~K}, 15 \mathrm{~K} \& 25 \mathrm{~K}(\mathrm{~A})$ ) which were further analyzed using $\mathrm{RT}^{2}$ Profiler PCR Array Data Analysis Version 3.5 from Qiagen. 15K and 25K (A) group shown anti-trends while 25K (A) trends for transcripts match those observed in $10 \mathrm{~K}$ and $\mathrm{BL}$.

d) Gene ontology analysis of lung proteome revealed that Binding and Protein binding processes dominate across all three groups while $25 \mathrm{~K}$ (A) group has molecular functions as the top- 
most molecular function. Pathway analysis (IPA) of plasma proteins reveals that LXR/RXR Activation is perturbed in $10 \mathrm{~K}$ (up-regulated; saffron; $\mathrm{z}$-score $>2$ ) and $15 \mathrm{~K}$ (down-regulated; blue; z-score $<2$ ) groups while its normalized in $25 \mathrm{~K}$ (A) (grey; z-score either zero or nonsignificant) group. Acute phase signaling remains the pathway with the maximum number of proteins across all three groups. A co-relation is indicated between the molecular functions in lung proteome and the perturbed pathway in plasma proteome.

\section{Figure 3. Redox processes and Acute phase signaling.}

a) ROS levels were measured in both lung and plasma using DCFH-DA assay. The assay was performed in triplicates with three readings per group per experiment. ROS levels in both lung (fold change 3 ) and plasma (fold change 2.5) increase in $10 \mathrm{~K}$, decrease in $15 \mathrm{~K}$ (Lung: fold change 1.5; Plasma: fold change 0.8 ) and finally increase marginally in $25 \mathrm{~K}$ (A) (Lung: fold change 2; Plasma: fold change 1.8). Results are presented as Mean \pm SEM. Mean was calculated from the three separate experimental replicates. * represents p-value $<0.0001$ in lung tissue while \# represents p-value $<0.0001$ in plasma.

b) MDA (malondialdehyde) levels were measured in both lung and plasma using TBARS assay. In lung, MDA levels increase slightly in $10 \mathrm{~K}$ group (fold change 2), become highest in $15 \mathrm{~K}$ group (fold change 5) and decline significantly in $25 \mathrm{~K}$ (A) group (fold change 1.6). In plasma, there is a slight increase in $10 \mathrm{~K}$ group (fold change 1.3) before subsequently declining in $15 \mathrm{~K}$ (fold change 0.7 ) and $25 \mathrm{~K}$ (A) (fold change 0.5 ). Results are presented as Mean \pm SEM. Mean was calculated from the three separate experimental replicates. * represents p-value $<0.0001$ in lung tissue while \# represents p-value $<0.0001$ in plasma.

c) Expanded view (representative of $15 \mathrm{~K}$ group) of IPA mined Acute phase signaling pathway with overlaid up-regulated (red) and down-regulated (green) proteins identified in plasma proteome (Supplementary dataset S3).

d) Monocyte chemoattractant protein-1 (MCP-1) levels were measured in plasma. It is an indicator of monocyte activity and inflammatory stimuli. MCP-1 levels increased sharply in $10 \mathrm{~K}(0.6 \mathrm{ng} / \mathrm{ml})$ and $15 \mathrm{~K}(0.8 \mathrm{ng} / \mathrm{ml})$ before declining sharply in $25 \mathrm{~K}(\mathrm{~A})(0.1 \mathrm{ng} / \mathrm{ml})$. Results are presented as Mean \pm SEM. Mean was calculated from three separate experimental replicates. * represents p-value $<0.0001$.

e) Sulfotransferase 1A1 (Sult 1A1) levels were measured in plasma. It is an indicator of hypoxic stress and found elevated in HAPE patients' plasma[23]. ELISA results show it increases in $10 \mathrm{~K}(1600 \mu \mathrm{mol} / \mathrm{l})$ and $15 \mathrm{~K}(2200 \mu \mathrm{mol} / \mathrm{l})$ as compared to Baseline (BL; $1500 \mu \mathrm{mol} / \mathrm{l})$ while levels in $25 \mathrm{~K}$ (A) group are almost equal to BL. Results are presented as Mean $\pm \mathrm{SEM}$. Mean was calculated from the three separate experimental replicates. * represents p-value $<0.0001$.

f) Representative immunoblots of STAT-3 and Calpain-2 in plasma with bar-graphs showing differential levels of both proteins. STAT-3 levels increase drastically in $15 \mathrm{~K}$ group $(10,000$ $\mathrm{AU})$ while other groups have similar levels (approx. 5,000-7,000 AU). Calpain-2 decreases in $10 \mathrm{~K}(6,000 \mathrm{AU})$ and $15 \mathrm{~K}(4,000 \mathrm{AU})$ group as compared to BL (9,000 AU) with significant recovery in $25 \mathrm{~K}$ (A) group (8,000 AU). The anti-trends observed in STAT-3 and Calpain-2 levels across the four groups indicate a systemic transcriptional activation and downregulation of proteolysis that reaches its peak in $15 \mathrm{~K}$ group and is reverted to BL levels in $25 \mathrm{~K}$ (A) groups. Results are presented as Mean \pm SEM of autoradiograms' pixel intensities (Arbitrary units). Mean was calculated from three separate experimental replicates. * represents p-value $<0.0001$. 


\section{Figure 4. Nrf2 signaling in lung and its downstream systemic effects.}

a) Representative immunoblots of Nrf2 and PRDX6 in lung tissue and of GPX3 and TR2 in plasma with bar-graph depicting their levels in each group. Lung tissue: Nrf2 levels increase in $10 \mathrm{~K}(22,000 \mathrm{AU})$, decrease in $15 \mathrm{~K}(12,000 \mathrm{AU})$ and revert to BL levels $(16,000 \mathrm{AU})$ in 25K (A) group. PRDX6 slightly decrease in 10K (14,000 AU), decline drastically in 15K (1000 AU) and recover sharply in $25 \mathrm{~K}(\mathrm{~A})(11,000 \mathrm{AU})$ as compared to $\mathrm{BL}(17,000 \mathrm{AU})$. Plasma: GPX3 levels increase slightly in 10K (14,000 AU), increase further $(27,000 \mathrm{AU})$ and decline to close to normoxic levels $(11,000 \mathrm{AU})$ in $25 \mathrm{~K}$ (A) group. TR2 levels decline noticeably in $15 \mathrm{~K}$ group $(7,000 \mathrm{AU})$ and recover close to normoxic levels $(11,000 \mathrm{AU})$ in $25 \mathrm{~K}$ (A) group. Results are expressed as Mean \pm SEM of autoradiograms' pixel intensities (Arbitrary units). Mean was calculated from three separate experimental replicates. * represents p-value $<0.0001$.

b) Fold change values of select redox-stress specific transcripts from PCR-Array performed using lung tissue. Across major antioxidants' transcripts $15 \mathrm{~K}$ group samples show declining levels, except in Txnrd2 (TR2) which shows increased fold change in 15K group.

c) ELISA was performed on lung tissues and plasma to assess Hemopexin levels. In lung tissue, hemopexin declines in $10 \mathrm{~K}$ ( 0.1 fold change $)$ and $15 \mathrm{~K}$ groups $(0.25$ fold change $)$ and rebounds to normoxic levels (1.0 fold change) in $25 \mathrm{~K}$ (A) group. In plasma, there is significant increase in hemopexin levels in $15 \mathrm{~K}$ (2.1 fold change) before levels decline in $25 \mathrm{~K}$ (A) (1.3 fold change) Bar graph depicts results from each group as Mean \pm SEM. Mean was calculated from three separate experimental replicates. * represents p-value $<0.0001$.

d) Bar graph depicting thioredoxin reductase 2 (TR2) activity levels in each group across lung tissue and plasma. In $15 \mathrm{~K}$ group, lung tissue show maximum decline in TR2 activity (1 unit/mg protein) while plasma has highest activity (19 units/mg protein). In $25 \mathrm{~K}$ (A) group, TR2 activity resurges in lung ( 3 units/mg protein) but declines in plasma ( 8 units/mg protein). Results are depicted as Mean \pm SEM. Mean was calculated from three separate experimental replicates. ${ }^{*}$ represents p-value $<0.0001$.

e) Bar graph depicting Superoxide dismutase (SOD) activity levels in each group across lung tissue and plasma. In $15 \mathrm{~K}$ group, lung tissue witness a decline in SOD activity $(0.2 \mathrm{units} / \mathrm{mg}$ protein) while plasma shows increased SOD activity ( 0.2 units $/ \mathrm{mg}$ protein). In $25 \mathrm{~K}$ (A) group, lung tissue has highest SOD activity (1.0 unit/mg protein) while plasma SOD activity declines $(0.1 \mathrm{unit} / \mathrm{mg}$ protein). Results are depicted as Mean \pm SEM. Mean is calculated from three separate experimental replicates. * represents p-value $<0.0001$.

f) Bar graph depicting total glutathione (GSH) concentration in all groups across lung tissue and plasma. In lung tissue, GSH levels increase in $10 \mathrm{~K}(75 \mu \mathrm{M})$, decrease in $15 \mathrm{~K}(47 \mu \mathrm{M})$ and increase again in $25 \mathrm{~K}(\mathrm{~A})(65 \mu \mathrm{M})$. In plasma, GSH levels decrease slightly in $10 \mathrm{~K}(5 \mu \mathrm{M})$, increase in $15 \mathrm{~K}(13 \mu \mathrm{M})$ and fall back close to normoxic levels $(7 \mu \mathrm{M})$ in $25 \mathrm{~K}(\mathrm{~A})$. Results are depicted as Mean \pm SEM. Mean was calculated from three separate experimental replicates. * represents p-value $<0.0001$.

\section{Figure 5. Cytoskeletal stability in 25K (A) group.}

a) Fold change values of various lung cytoskeletal proteins as observed in LC-MS/MS dataset. Across all cytoskeletal proteins, $15 \mathrm{~K}$ group shows notable decline while $25 \mathrm{~K}$ (A) group shows appreciable rebound.

b) Representative immunoblots of Vimentin, Actin and Tubulin in lung tissue. Vimentin levels decrease till $15 \mathrm{~K}$ group with rebound in $25 \mathrm{~K}$ (A) group. Actin levels decrease significantly in $10 \mathrm{~K}$ and $15 \mathrm{~K}$ groups with $25 \mathrm{~K}$ (A) showing levels close to baseline. Tubulin levels also 
decline in $15 \mathrm{~K}$ with rebound in $25 \mathrm{~K}$ (A) group at a level close to baseline. Immunoblotting results are depicted as Mean \pm SEM of autoradiograms' pixel intensities (Arbitrary units). Mean was calculated from three separate experimental replicates. * represents pvalue $<0.0001$.

c) Bar graph representing free $\mathrm{Ca}^{2+}$ concentration in lung tissue across four groups. $15 \mathrm{~K}$ group shows significant increase in $\mathrm{Ca}^{2+}$ concentration $(4.7 \mathrm{mg} / \mathrm{dL})$ as compared to baseline $(2$ $\mathrm{mg} / \mathrm{dL})$ while $10 \mathrm{~K}$ and $15 \mathrm{~K}$ groups $(1.5 \mathrm{mg} / \mathrm{dL}$ approx $)$ show slight decreases. Results are represented as Mean \pm SEM. Mean was calculated from three experimental replicates. * represents p-value $<0.0001$.

\section{Figure 6. Restored energy homeostasis in 25K (A) group.}

a) Expanded view of LXR/RXR Activation pathway from IPA. The various downstream metabolic processes modulated by LXR/RXR such as cholesterol metabolism and lipogenesis as well as upstream molecules like Bile acid and oxysterols are shown.

b) Clustergram of $10 \mathrm{~K}, 15 \mathrm{~K}$ and $25 \mathrm{~K}$ (A) with baseline fold change values taken as 1 for lung proteins involved in energy homeostasis and metabolism. Color brown indicates up-regulation while blue indicates down-regulation with white indicating neutral fold change. Fold change values were subtracted from baseline fold change (1) for each protein across all groups to arrive at final fold change values for clustergram. $15 \mathrm{~K}$ and $25 \mathrm{~K}$ (A) groups show complete anti-trends with $10 \mathrm{~K}$ showing similarity with both the groups.

c) Representative immunoblots and respective bar graphs of Retinoid X receptor (RXR) and Malate dehydrogenase (MDH) in plasma and Glyceraldehyde 3-phosphate Dehydrogenase (GAPDH) in lung tissue. RXR and MDH (plasma) have maximal levels in $15 \mathrm{~K}$ group with decline in $25 \mathrm{~K}$ (A) group at levels similar to $10 \mathrm{~K}$ group. GAPDH (lung) shows minimal levels in $15 \mathrm{~K}$ group with increase in $25 \mathrm{~K}$ (A) group to level close to $10 \mathrm{~K}$ group. Immunoblotting results are depicted as Mean \pm SEM of autoradiograms' pixel intensities (Arbitrary units). Mean was calculated from three separate experimental replicates. * represents p-value $<0.0001$.

d) $\mathrm{NAD} / \mathrm{NADH}$ ratio was estimated in lung tissue. $15 \mathrm{~K}$ group has highest ratio of NAD/NADH suggesting shift in pyruvate-lactate step towards lactate. 10K and 25K (A) groups show slight decrease in NAD/NADH ratio as compared baseline. Results are depicted as Mean \pm SEM. Mean was calculated from three experimental replicates. * represents p-value $<0.005$.

\section{Figure 7. Putative protein cascades involved in rapid acclimatization in 25K (A) group.}

Figure represents protein networks and processes involved in redox homeostasis, energy homeostasis, inflammatory signaling, protein misfolding and cytoskeletal (alveolar) integrity for $25 \mathrm{~K}$ (A). Dotted black lines represent events derived from literature. Bold black lines represent experimental findings. Central signaling molecules like STAT-3, Nrf and RXR begin cascade. STAT-3 levels fall back to normoxic levels in $25 \mathrm{~K}$ (A) group plasma causing lowered inflammatory signaling, increased VDR/RXR signaling and increased anti-oxidant response. Lowered inflammatory signaling is observed via MCP-1 levels as well as increased Calpain-2 levels. Increased VDR/RXR signaling helps restore energy homeostasis in $25 \mathrm{~K}$ (A) group as compared to $15 \mathrm{~K}$ group which is observed via NAD/NADH ratio and increased levels of glycolytic enzymes. VDR also plays a small role in calcium homeostasis. Free $\mathrm{Ca}^{2+}$ levels are reduced significantly in $25 \mathrm{~K}$ (A) group. This helps restore levels of cytoskeletal proteins with housekeeping functions. This, in part, causes alveolar structural integrity to endure extreme hypobaric conditions. Reduction in free $\mathrm{Ca}^{2+}$ levels also improves Calpain-2 levels. Actin is required for Nrf2 translocation into nucleus. When levels of actin are restored, Nrf2 mediated 
oxidative stress response is activated. Inflammatory signaling is further reduced due to it. Also, antioxidant protein levels increase to strengthen redox homeostasis. This entire process occurs within lung and plasma. Thus, proteins like GPX3, SOD1, HPX, CAT, MDH-1, STAT-3, TR2, RXR, Tubulin, Sult $1 \mathrm{~A} 1$ and MCP-1 can provide important clues regarding the acclimatization status when their levels at normoxia and extreme hypobaric hypoxia (as in $25 \mathrm{~K}$ (A) group) are compared on following the stated acclimatization strategy of $10 \mathrm{~h}$ at $15,000 \mathrm{ft}$ followed by $1 \mathrm{~h}$ of normobaric normoxia exposure.

TABLE 1: 2D-MALDI-TOF/TOF identified proteins with Uniprot ID and normalized fold change values across each group.

\begin{tabular}{|c|c|c|c|c|c|c|}
\hline S.No. & UniprotID & Protein ID & Normoxia & 10K & 15K & 25K(A) \\
\hline 1 & P02770 & Serum albumin & 1 & 0.69564562 & 0.632728273 & 1.123398116 \\
\hline 2 & J3QLIO & Beta-2-glycoprotein 1 APO H & 1 & 0.599191064 & 0.442797632 & 0.98672265 \\
\hline 3 & P20059 & Hemopexin & 1 & 1.078078586 & 1.702732484 & 1.580064789 \\
\hline 4 & P04276 & Vitamin D-binding protein & 1 & 1.099381524 & 0.614069314 & 0.951075257 \\
\hline 5 & P02680 & Fibrinogen gamma chain & 1 & 0.506130817 & 0.343636037 & 1.268732041 \\
\hline 6 & P48199 & C-reactive protein & 1 & 0.960973541 & 0.178058842 & 0.677460411 \\
\hline 7 & P23764 & Glutathione peroxidase 3 & 1 & 1.451303161 & 8.596477529 & 1.390318158 \\
\hline 8 & P02767 & Transthyretin & 1 & 0.864864807 & 0.598442174 & 0.871346305 \\
\hline
\end{tabular}

Except Hemopexin and Glutathione peroxidase 3, all other proteins identified show a decline in all three groups. 


\section{Figure 1}

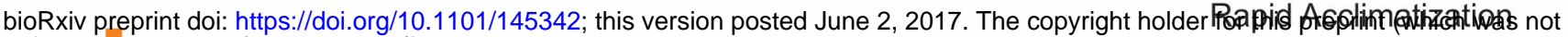

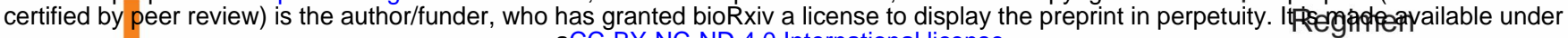

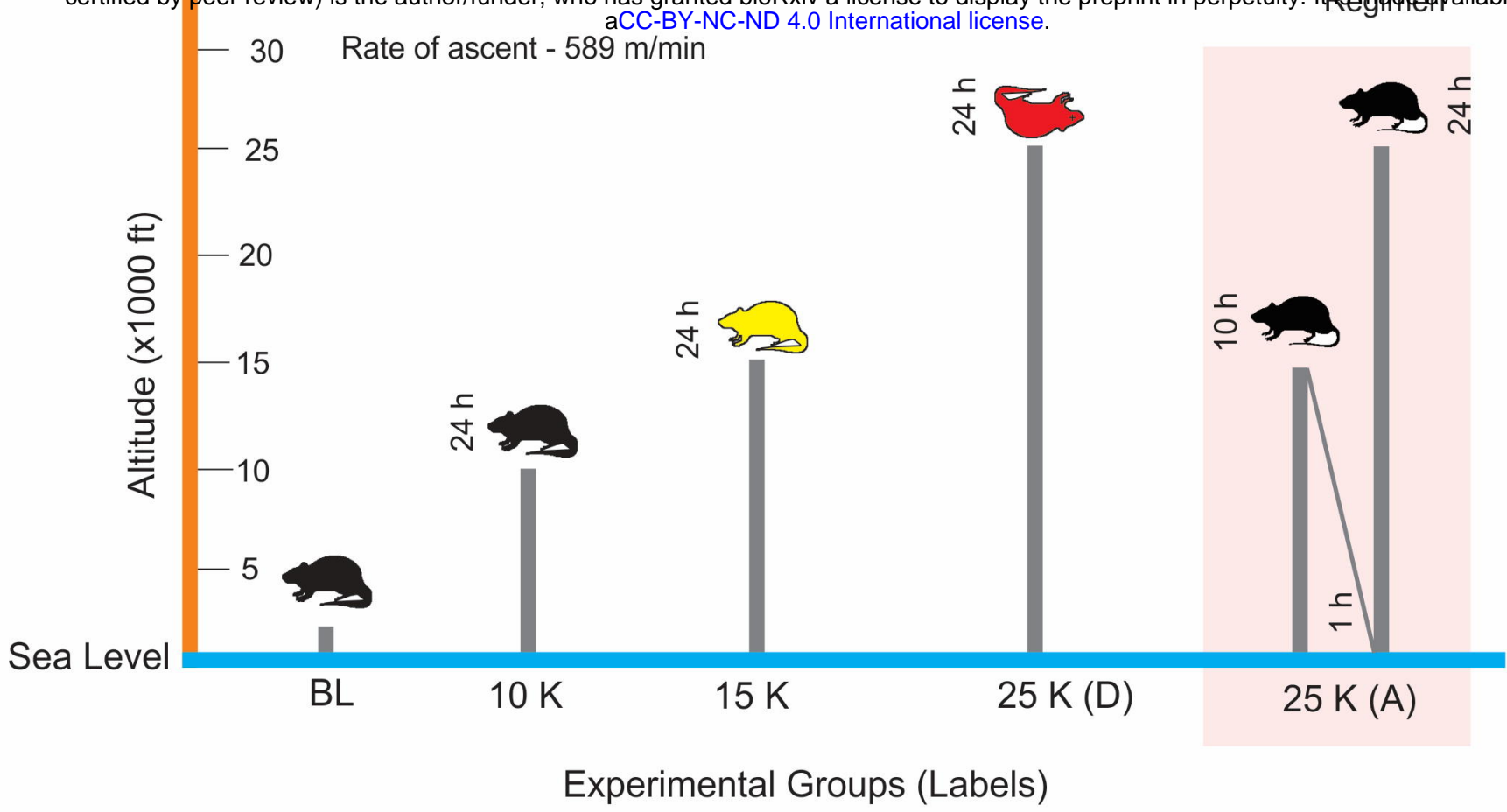


Figure 2

a

bioRxiv preprint doi: https://doi.org/10.1101/145342; this version posted June 2, 2017. The copyright holder for this preprint (which was not certified by peer review) is the author/funder, who has granted bioRxiv a license to display the preprint in perpetuity. It is made available under

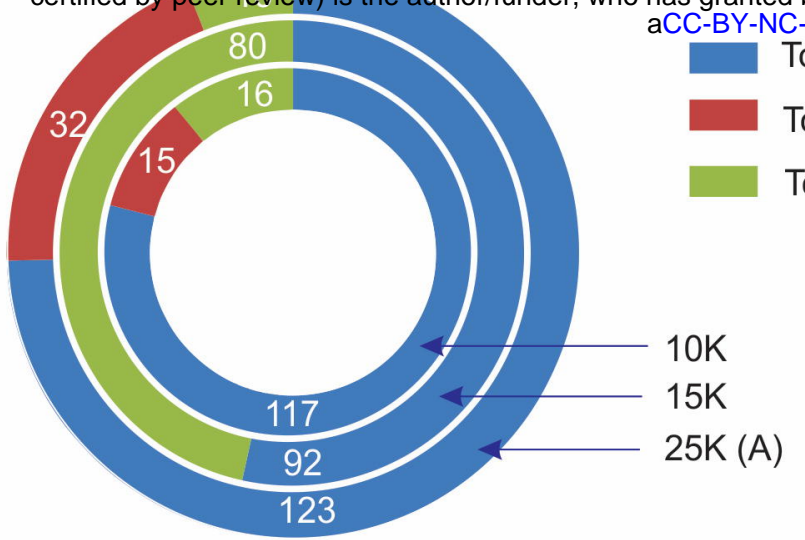
Total proteins identified

Total up regulated $(>1.5$ fold)

Total down regulated $(<0.67$ fold $)$

b
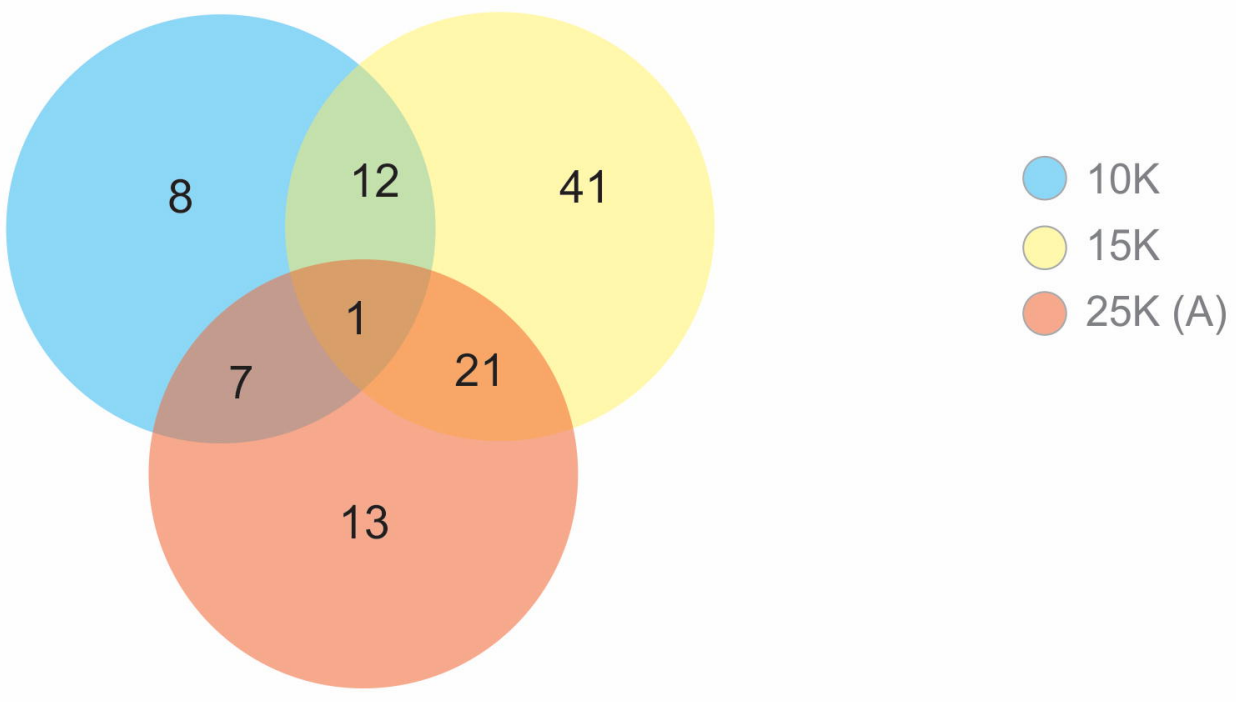

d

$10 \mathrm{~K}$

1

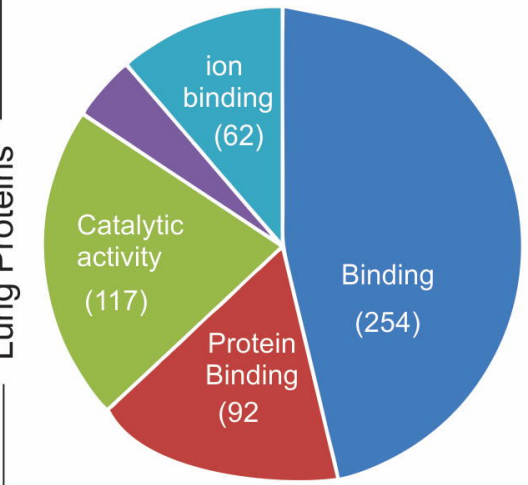

造

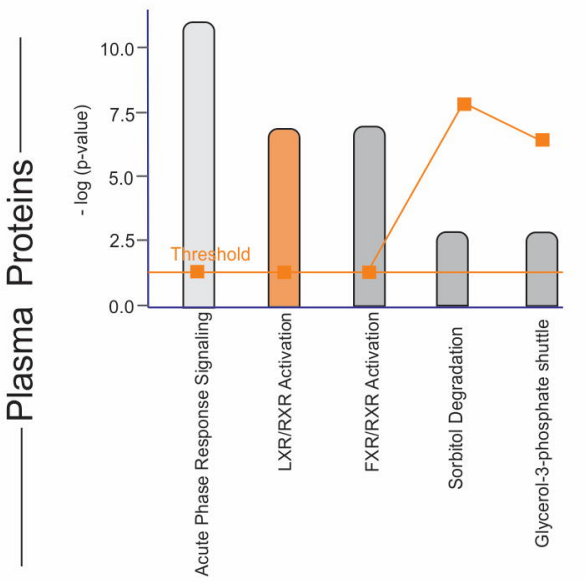

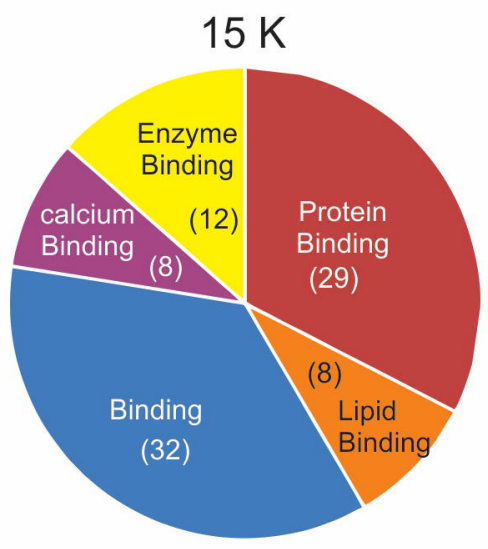
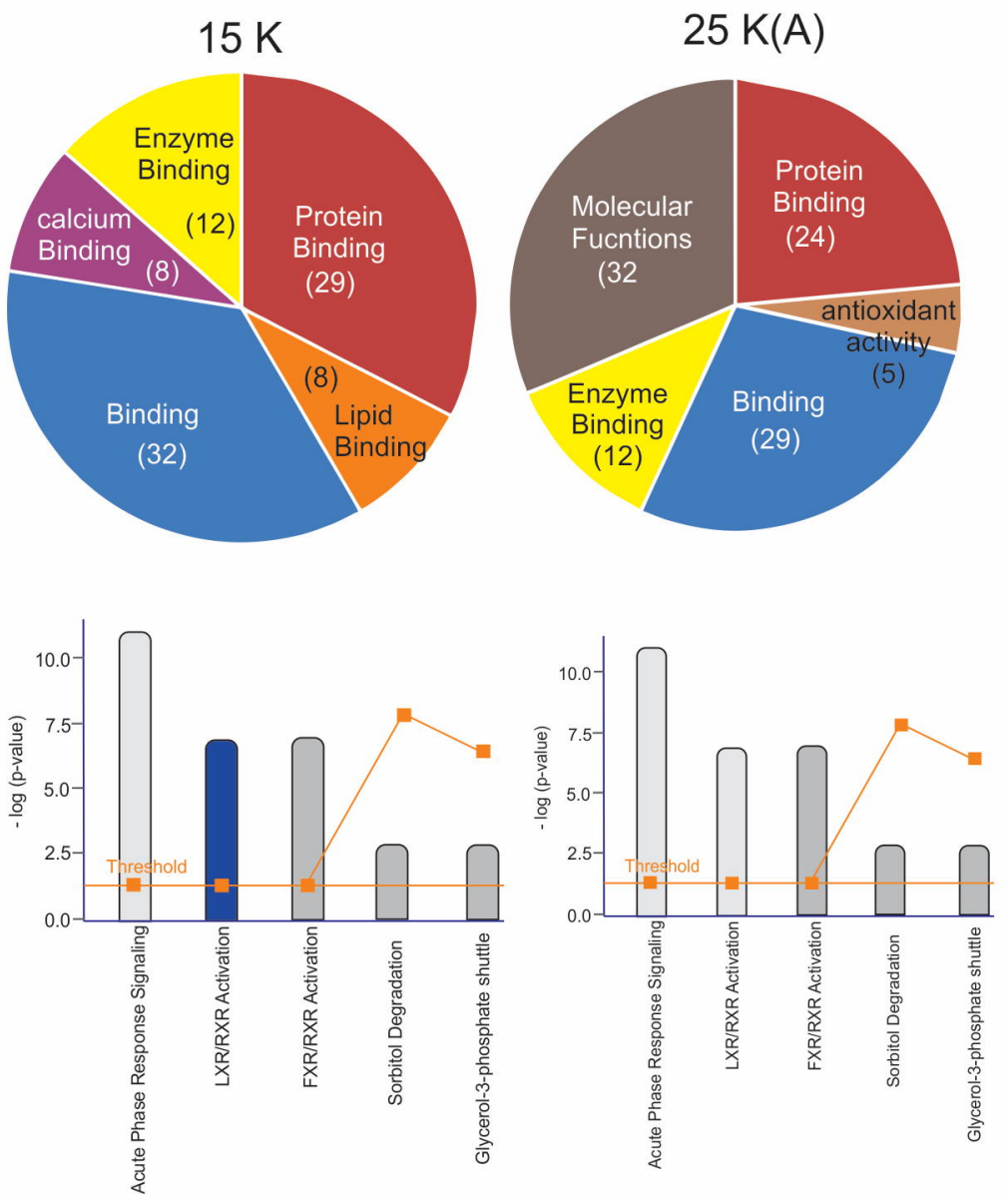

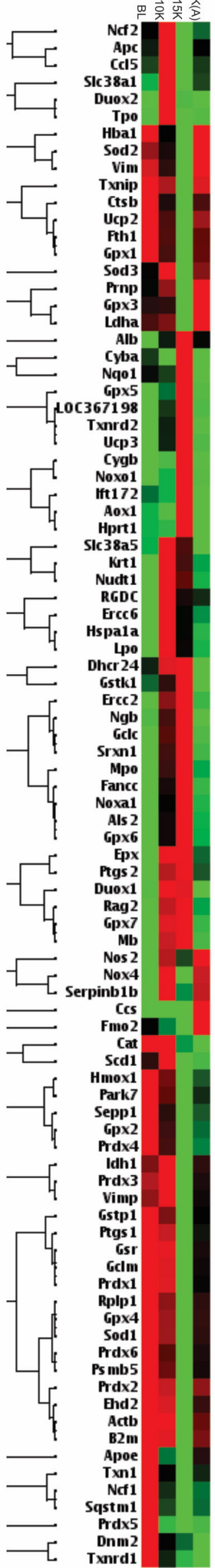


Figure 3

a bioRxiv preprint doi: https://doi.org/10.1101/145342; this version posted JWPe 2, 2017. The copyright holder for this preprint (which was not certified by peer review) is the author/funder, who has granted bioRxiv a license to display the preprint in perpetuity. It is made available under aCC-BY-NC-ND 4.0 International license.
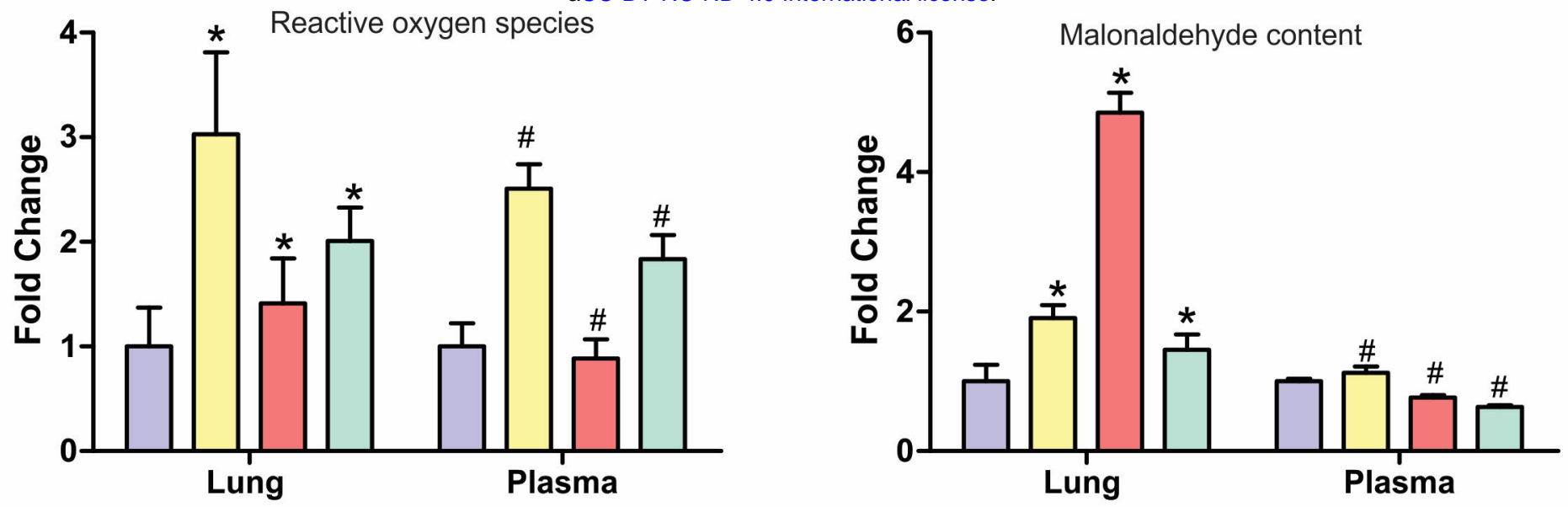

C

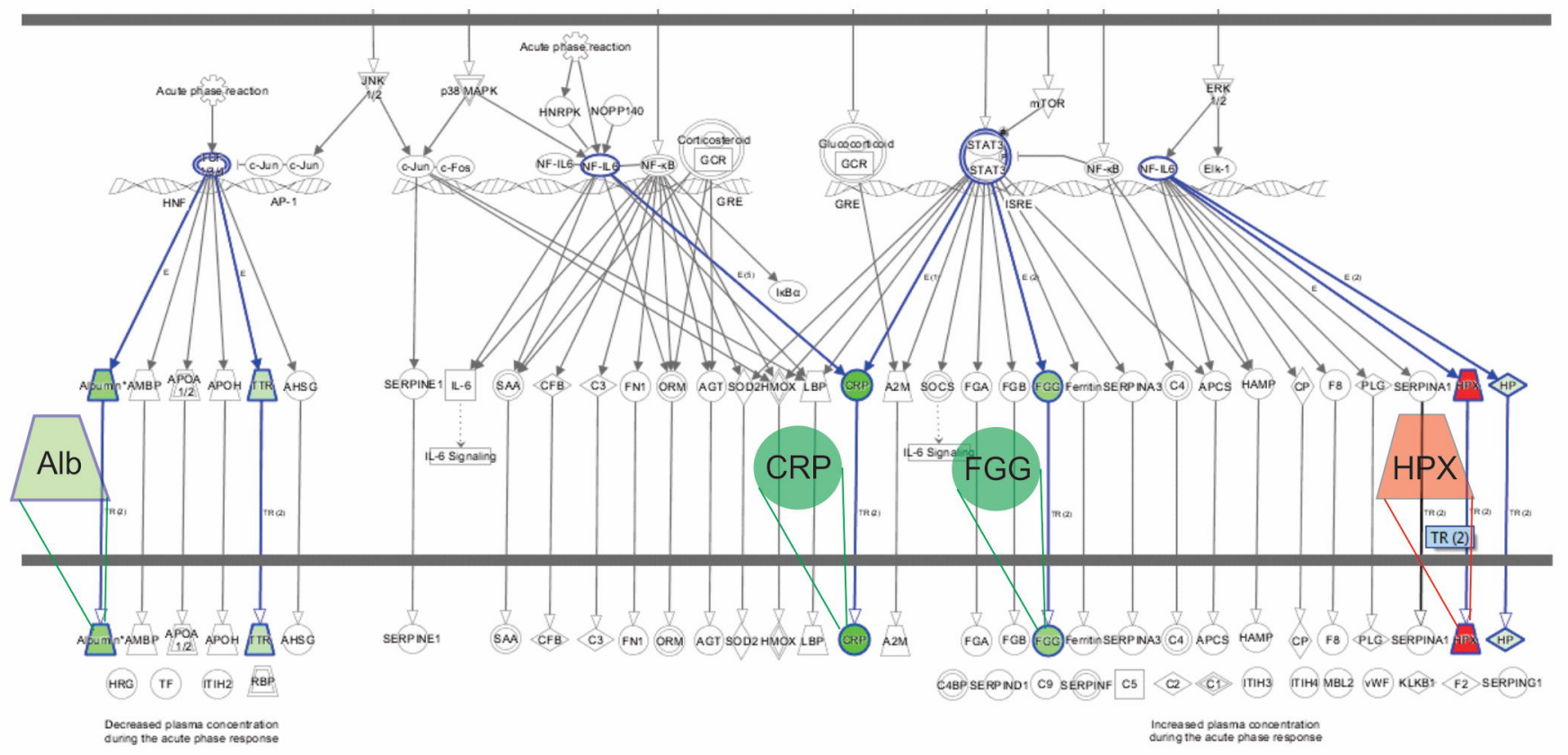

d

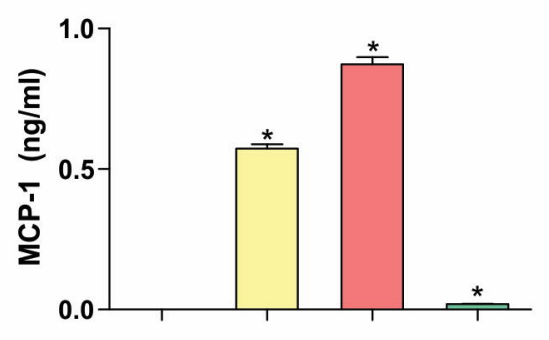

e

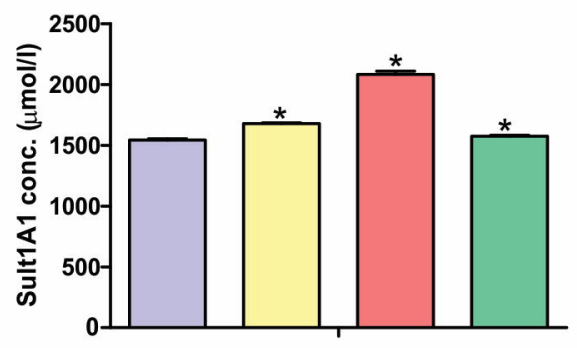

$\mathrm{BL} 10 \mathrm{~K} 15 \mathrm{~K} \quad 25 \mathrm{~K}(\mathrm{~A})$

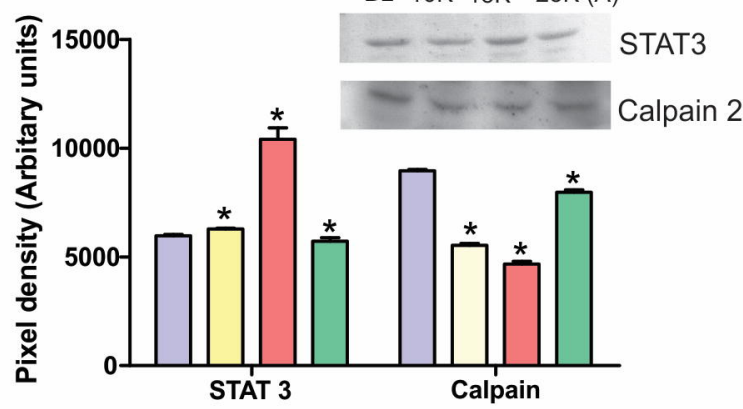

$10 \mathrm{~K}$ 
Figure 4

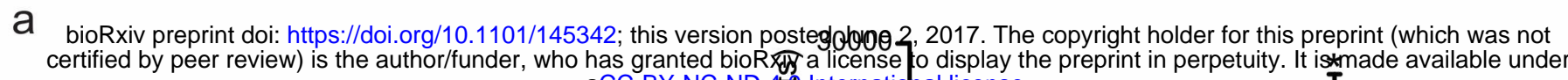
$\mathrm{BL} \quad 10 \mathrm{~K} \quad 15 \mathrm{~K} \quad 25 \mathrm{~K}(\mathrm{~A})$
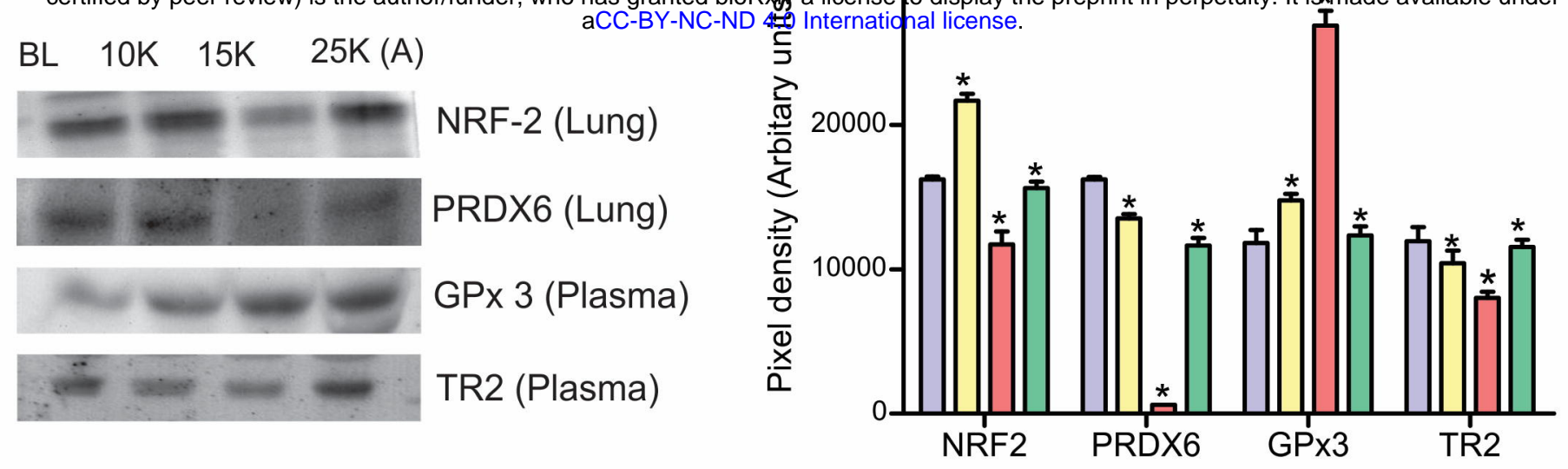

b
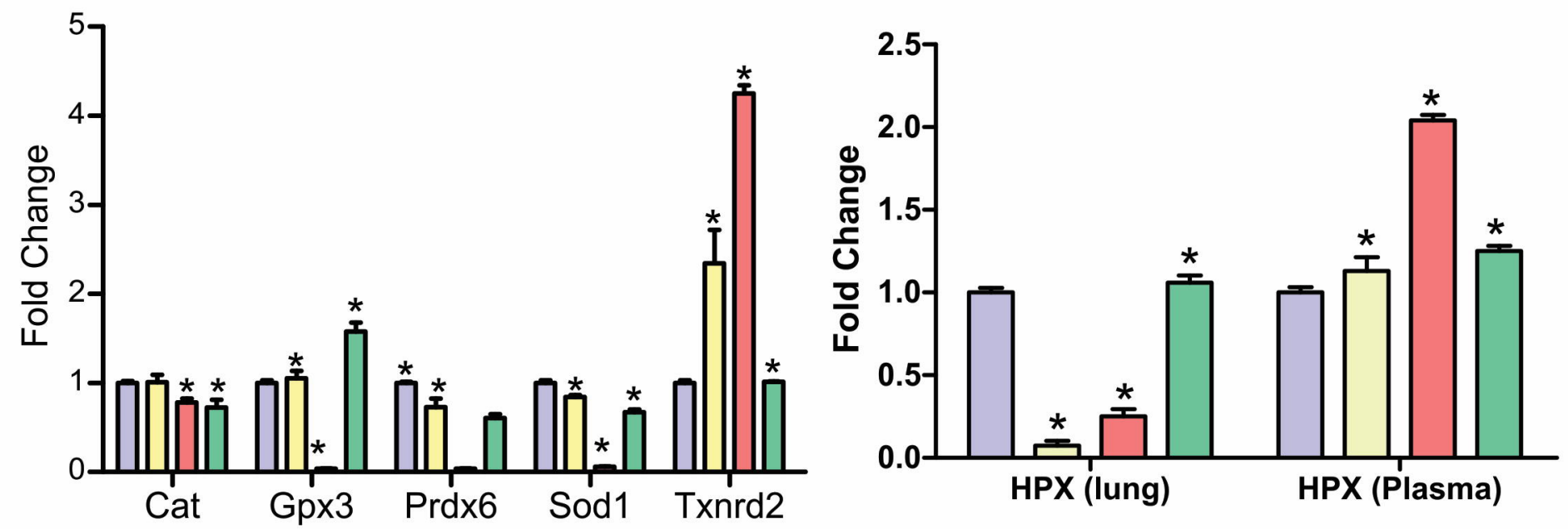

d

e

f
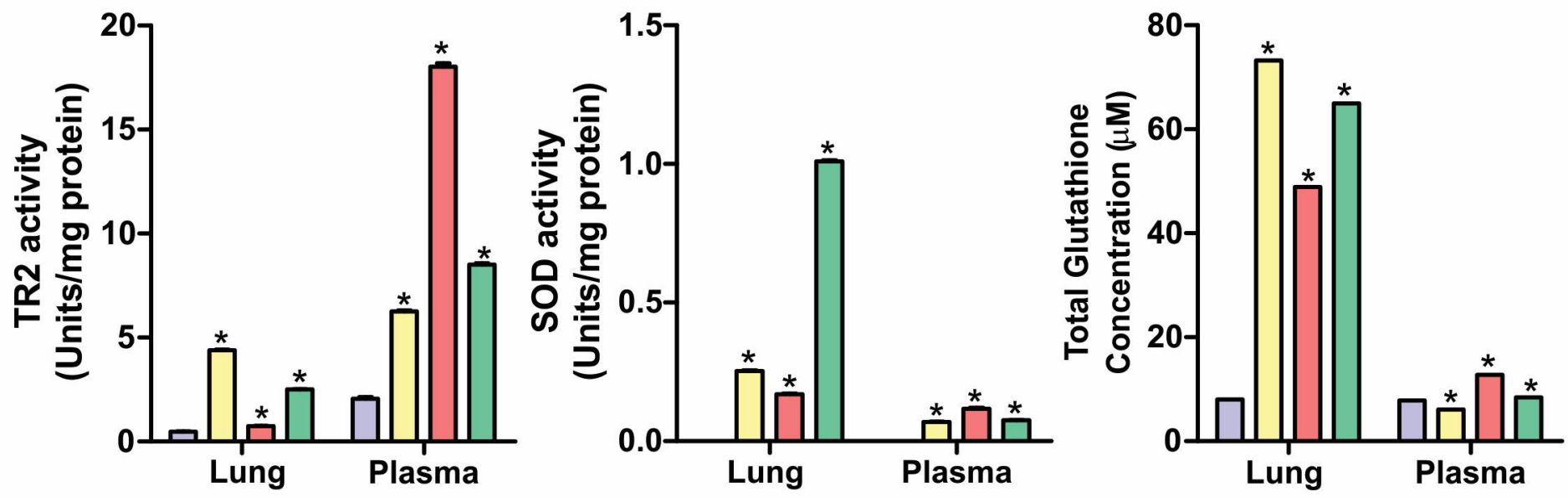

$B L$ 
Figure 5

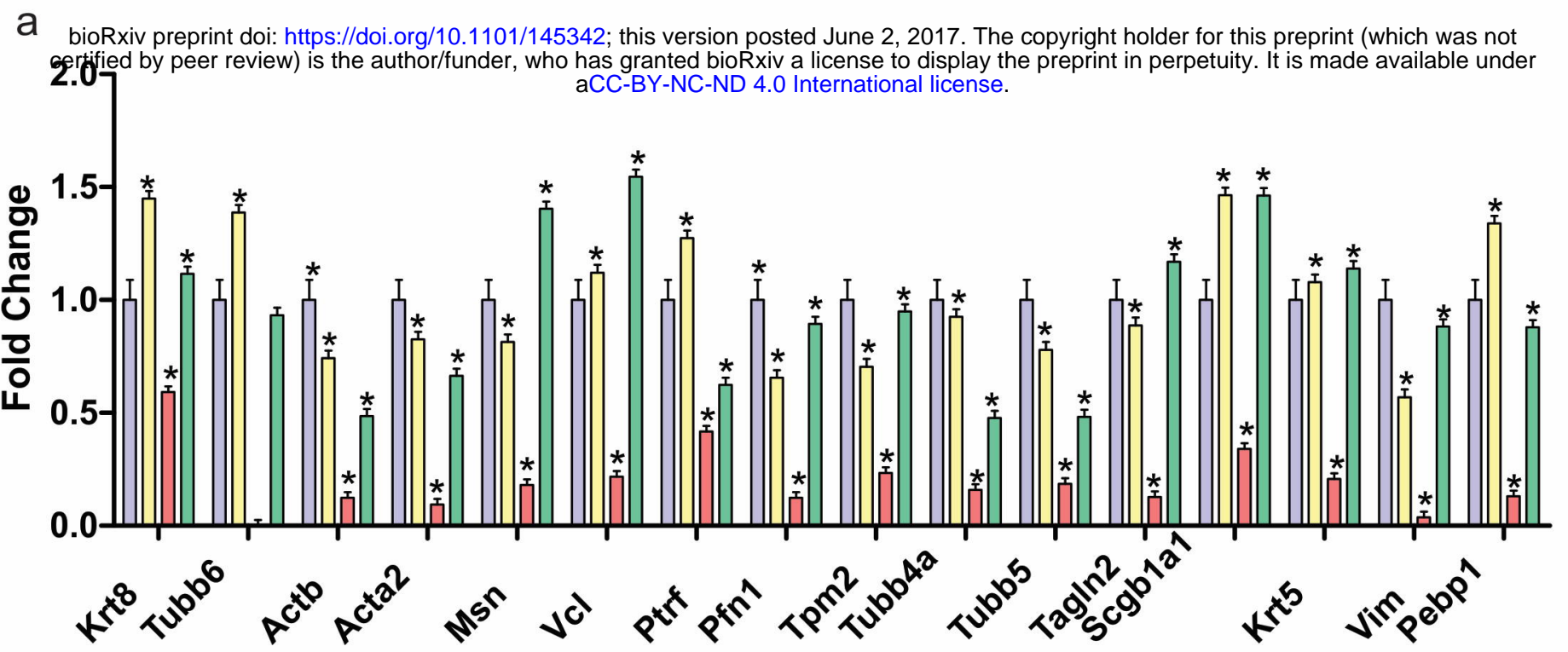

b

BL $\quad 10 \mathrm{~K} \quad 15 \mathrm{~K} \quad 25 \mathrm{~K}(\mathrm{~A})$
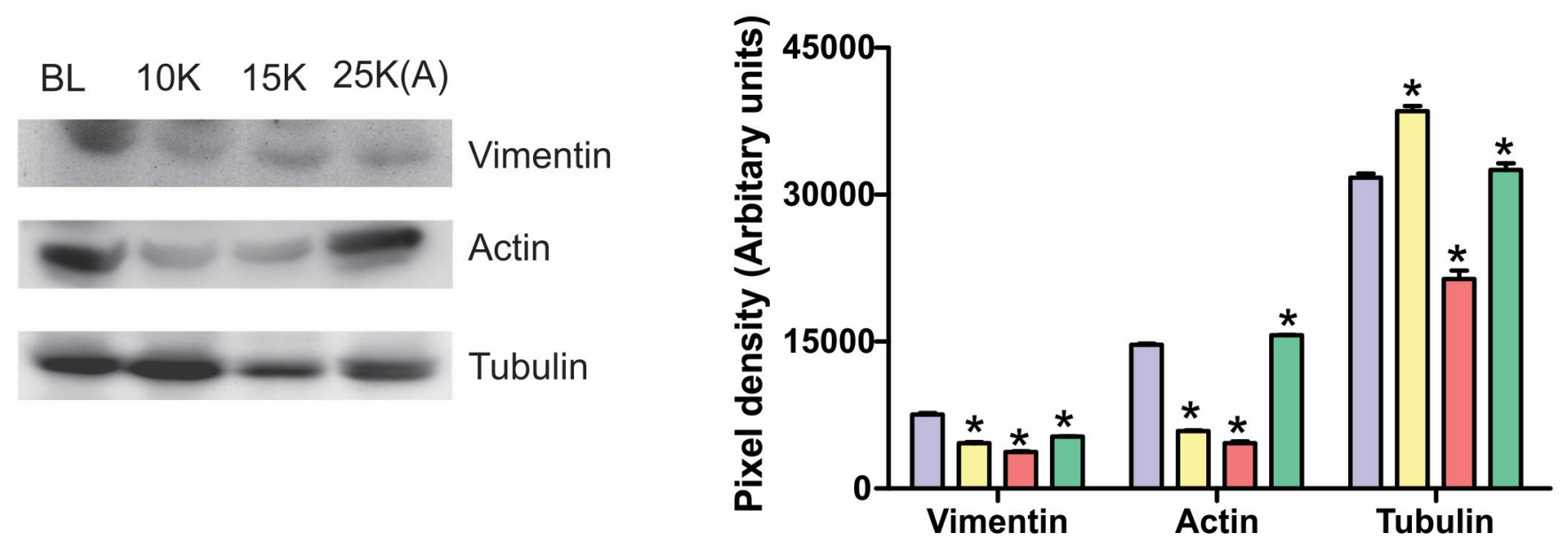

C

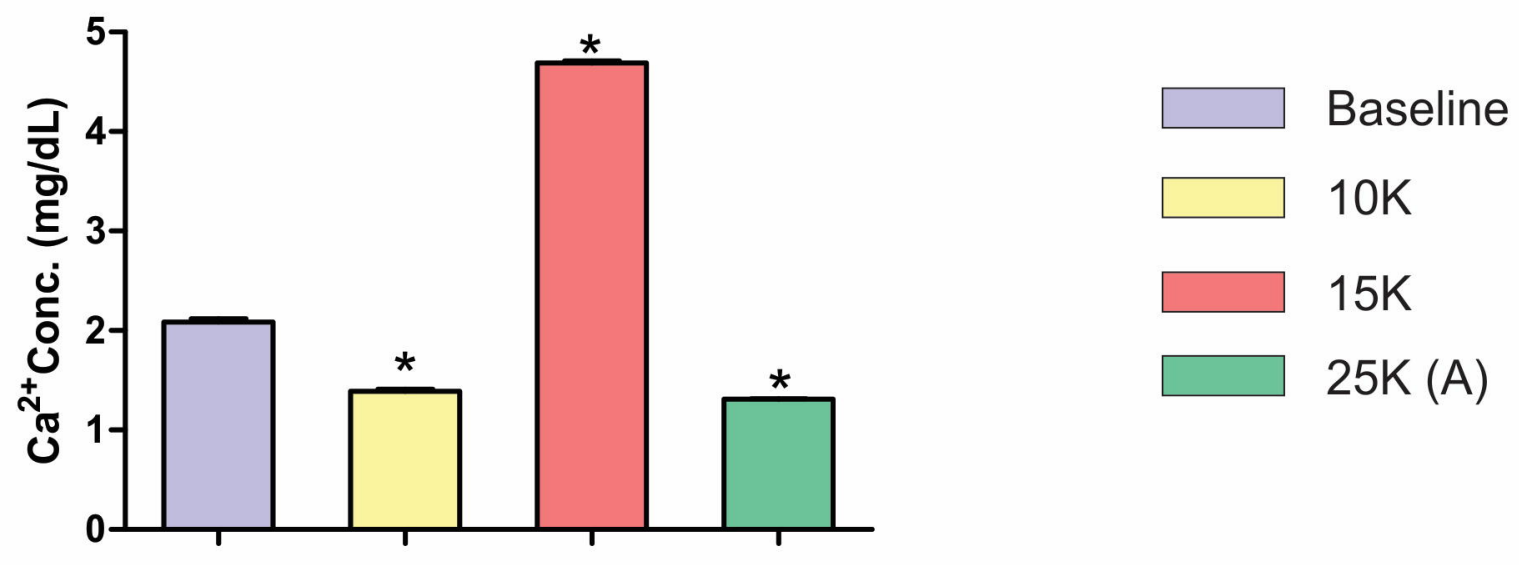




\section{Figure 6}

a bioRxiv preprint doi: https://doi.org/10.1101/145342; this version posted June 2, 2017. The cbpyright holder for this preprint (which was not certified by peer review) is the author/funder, who has granted bioRxiv a license to display the preprint in perpetuity. It is made available under
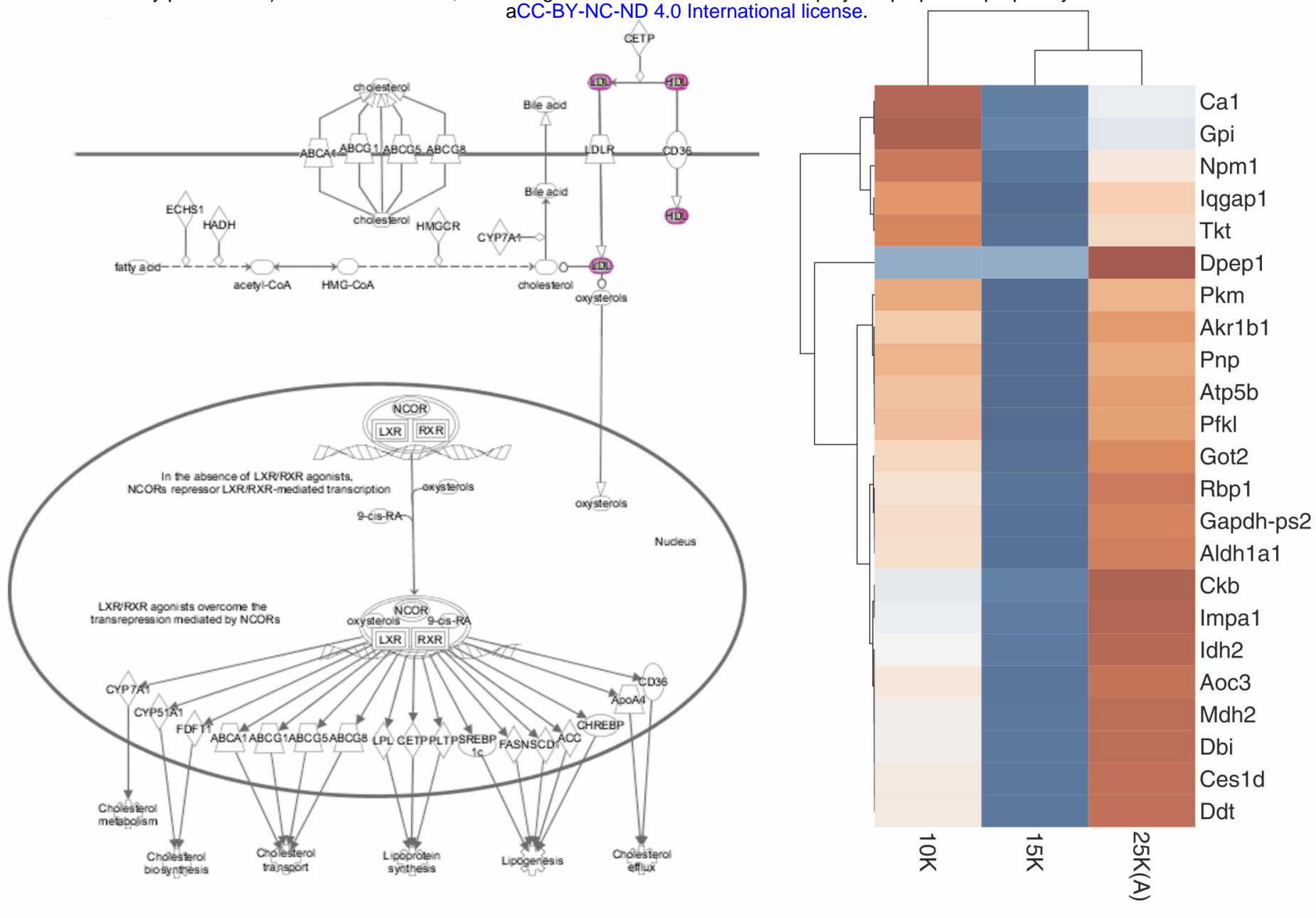

C
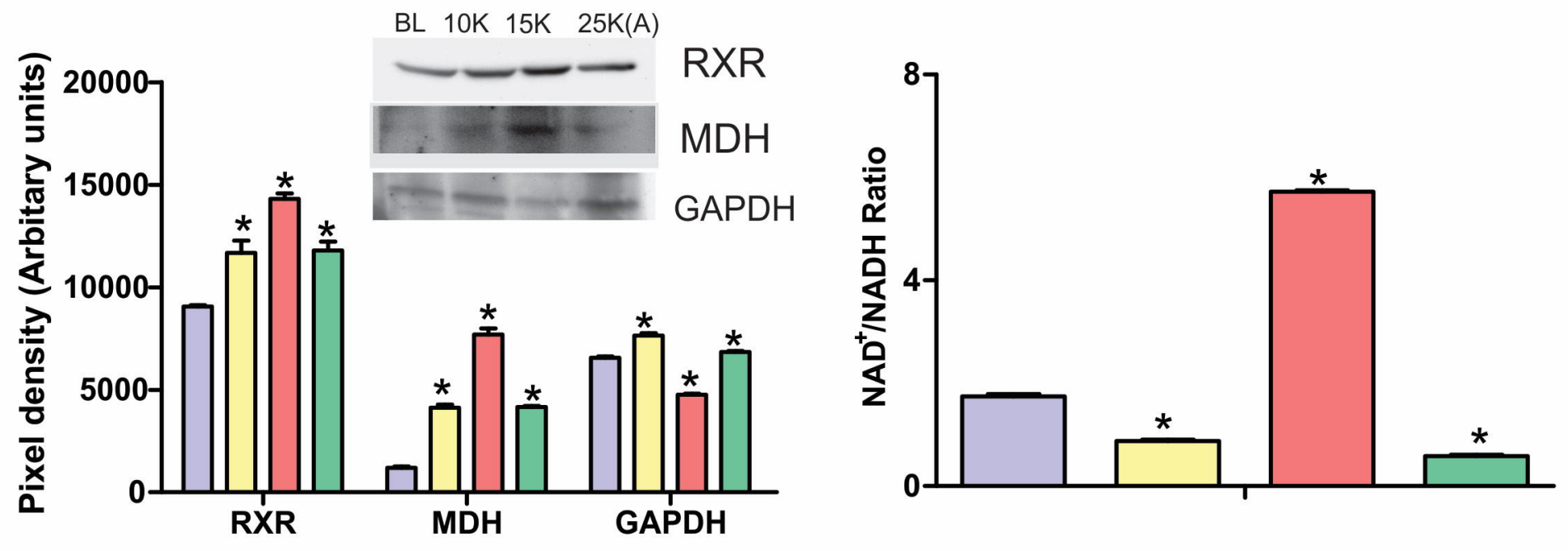

$\mathrm{BL}$ 
$25000 \mathrm{ft}(24 \mathrm{~h})$ 25K (A) Group

\section{Normoxia}

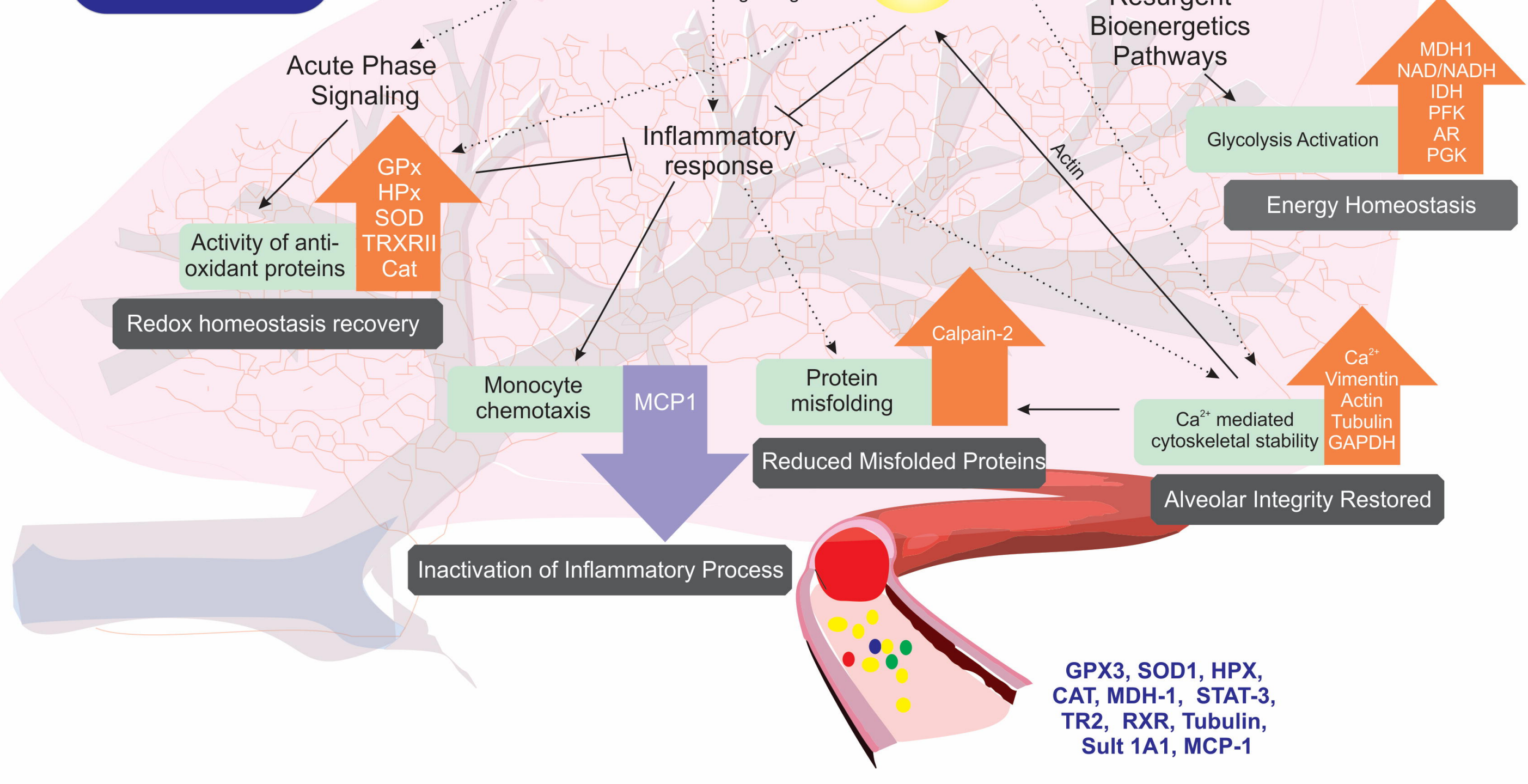

